\title{
EFICIÊNCIA AGRONÔMICA DE FOSFATOS COM SOLUBILIDADE VARIÁVEL EM ÁGUA EM SOLOS DISTINTOS QUANTO A CAPACIDADE DE FIXAÇÃO DE FÓSFORO
}

\author{
JACK FERNANDO SANTOS QUISPE
}

Dissertação apresentada à Escola Superior de Agricultura “Luiz de Queiroz”, da Universidade de São Paulo, para obtenção do título de Mestre em Agronomia, Área de Concentração: Solos e Nutrição de Plantas.

P I R A C I C A B A

Estado de São Paulo - Brasil

Setembro - 2004 


\section{EFICIÊNCIA AGRONÔMICA DE FOSFATOS COM SOLUBILIDADE VARIÁVEL EM ÁGUA EM SOLOS DISTINTOS QUANTO A CAPACIDADE DE FIXAÇÃO DE FÓSFORO}

\section{JACK FERNANDO SANTOS QUISPE}

Bacharel em Agronomia

Orientador: Prof. Dr. LUÍS IGNÁCIO PROCHNOW

Dissertação apresentada à Escola Superior de Agricultura "Luiz de Queiroz", Universidade de São Paulo, para a obtenção do título de Mestre em Agronomia, Área de Concentração: Solos e Nutrição de Plantas.

PIRACICABA

Estado de São Paulo - Brasil

Setembro - 2004 


\section{Dados Internacionais de Catalogação na Publicação (CIP) DIVISÃO DE BIBLIOTECA E DOCUMENTAÇÃO - ESALQ/USP}

Santos Quispe, Jack Fernando

Eficiência agronômica de fosfatos com solubilidade variável em água em solos distintos quanto a capacidade de fixação de fósforo / Jack Fernando Santos Quispe. - Piracicaba, 2004.

$57 \mathrm{p}$.

Dissertação (mestrado) - - Escola Superior de Agricultura Luiz de Queiroz, 2004.

Bibliografia.

1. Eficiência agronômica 2. Fertilidade do solo 3. Fixação 4. Fosfatos I. Título

CDD 631.42

"Permitida a cópia total ou parcial deste documento, desde que citada a fonte - O autor" 
Aos meus pais Germán e Rufina

Pelo amor em todos os momentos

OFEREÇO

Ao meu irmão Carlos e minha irmã Nadia

Pelo amor e paciência durante a minha vida

DEDICO

.....Desde el instante del nacer soñamos y solo despertamos si morimos, el bien seguro por el mal dejamos y hambrientos de vivir jamás vivimos...

Gonzáles Prada 


\section{AGRADECIMENTOS}

Ao Prof. Dr. Luís Ignácio Prochnow, pelo ensino, orientação e paciência durante o transcorrer do curso;

À coordenação do curso em Solos e Nutrição de Plantas e aos professores do curso pela colaboração e apoio;

Ao amigo e colega de pós-graduação Eros Artur Bohac Francisco pela amizade e convivência;

Às colegas Francirose Shigaki, Graziela Braga e Daniela Benedito pela paciência e bondade;

Aos funcionários do departamento de Solos e Nutrição de Plantas - USP/ESALQ, em especial ao Fernando Baldesín e Dorival Grisotto pela ajuda na montagem dos experimentos na casa de vegetação e coleta de solos;

Aos técnicos Luís Silva Junior, Maria Elisabete Guimarães, Lúcia Helena Forti, Ednéia Mondoni e João Álvaro Granja, pela ajuda na realização das análises de solos, plantas e fertilizantes; 
Aos amigos do curso de pós-graduação que, direta e indiretamente, ajudaram com críticas e sugestões, em especial a Michel Alexandro Cambri, Fernando César Bachiega Zambrosi e Xosé Luís Otero;

À Coordenação de Aperfeiçoamento de Pessoal de Nível Superior (CAPES) pela concessão da bolsa de estudos;

A DEUS 


\section{SUMÁRIO}

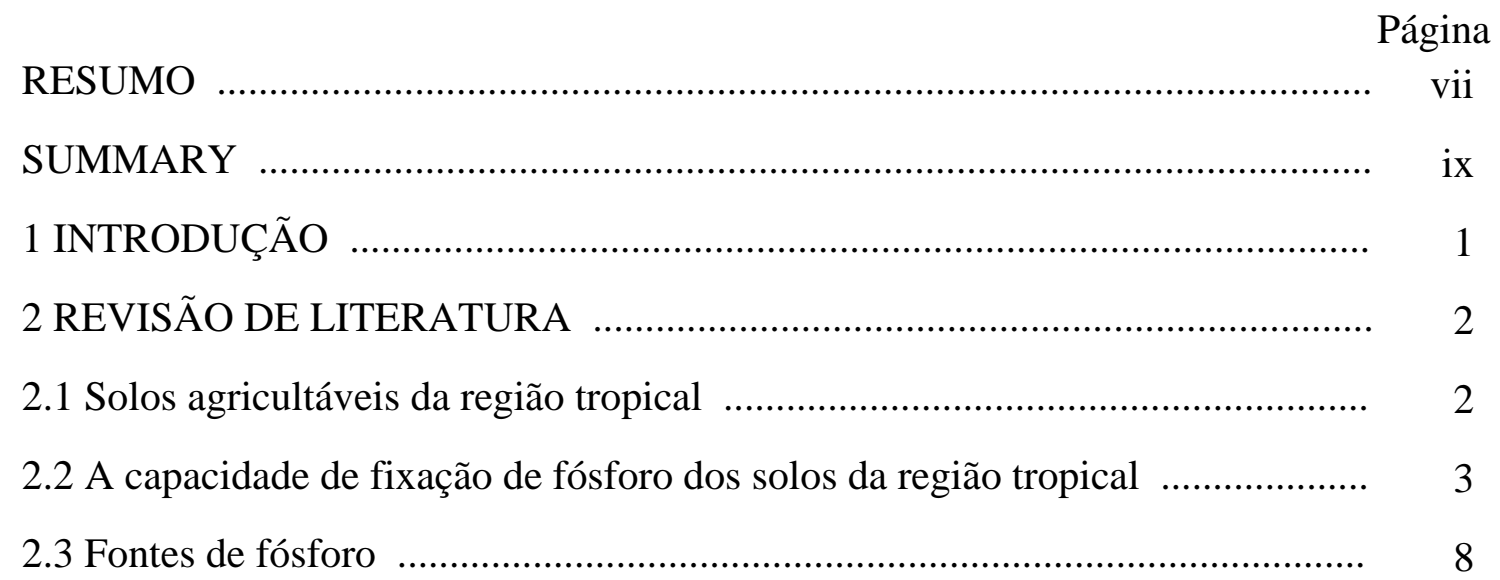

2.4 Eficiência agronômica dos fertilizantes fosfatados em solos de elevada capacidade de fixação de fósforo .............................................................. 10

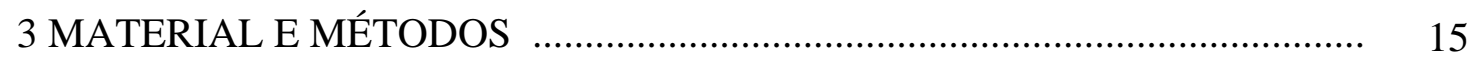

3.1 Definição dos solos para experimento em casa-de-vegetação ....................... 15

3.2 Caracterização dos solos utilizados no experimento em casa-de-vegetação ... 17

3.3 Fontes de fósforo utilizadas no experimento .............................................. 19

3.4 Avaliação da eficiência agronômica das fontes de fósforo em condições de casa-de-vegetação ................................................................................ 20

3.5 Análise estatística ............................................................................... 21

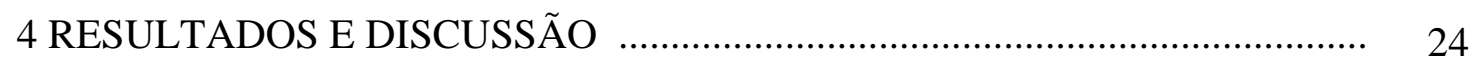

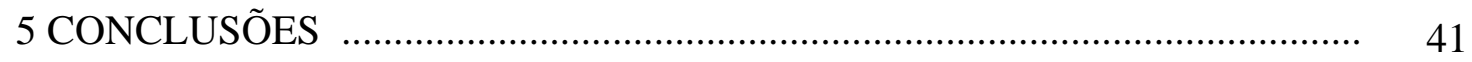

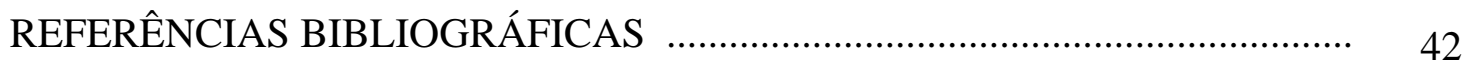

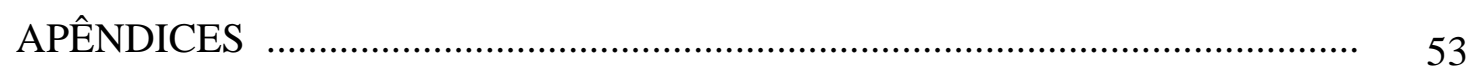




\title{
EFICIÊNCIA AGRONÔMICA DE FOSFATOS COM SOLUBILIDADE VARIÁVEL EM ÁGUA EM SOLOS DISTINTOS QUANTO A CAPACIDADE DE FIXAÇÃO DE FÓSFORO
}

\author{
Autor: JACK FERNANDO SANTOS QUISPE \\ Orientador: Prof. Dr. LUÍS IGNÁCIO PROCHNOW
}

\section{RESUMO}

O experimento foi desenvolvido no período de fevereiro a março de 2004, e se utilizou um delineamento estatístico de blocos completos ao acaso em arranjo fatorial com cinco fontes de fósforo, quatro doses, dois tipos de solos: (i) de elevada capacidade de fixação (Latossolo Vermelho) e (ii) de baixa capacidade de fixação (Latossolo Amarelo); duas testemunhas sem fósforo e três repetições (126 unidades experimentais). O estudo em casa de vegetação avaliou o efeito da capacidade de fixação sobre a eficiência agronômica relativa (EAR) de fontes alternativas de fósforo com solubilidade variável em água (superfosfato simples de baixa reatividade - LGSSP, multifosfato magnesiano - MFM, fosfato de rocha de Arad - FR, impureza catiônica do tipo H14 - H14) em relação ao padrão, o fosfato monocálcico - FMC, nas doses de aplicação de 12,5; 25; 50 e $100 \mathrm{mg} \mathrm{kg}^{-1}$ de $\mathrm{P}$ total. As amostras de terra foram peneiradas e misturadas com as fontes de fósforo em pó, e milho (Zea mays L. cultivar Sol da Manhã) foi cultivado durante cinco semanas até a colheita. A hipótese testada foi: fontes de fósforo com menor solubilidade em água, em relação às de elevada solubilidade, são mais eficientes 
em solos de elevada capacidade de fixação de fósforo. Em ambos os solos a produção de matéria seca e o valor de fósforo acumulado seguiram a ordem FMC > MFM = H-14 > LGSSP > FR. A EAR não guardou relação direta com a solubilidade em água ou em CNA $+\mathrm{H}_{2} \mathrm{O}$ das fontes de fósforo. A eficiência agronômica relativa das fontes com menor solubilidade em água foi maior no solo de mais elevada capacidade de fixação de fósforo quando da aplicação de doses mais baixas de fósforo, o que confirma a hipótese inicial. Sugerem-se novos estudos em condições de casa de vegetação e campo envolvendo, entre outros itens, situações distintas quanto a fontes (tipo e granulometria), tempo e sistemas de cultivo e solos. Novos dados poderão levar a uma melhor utilização das fontes alternativas contendo menor solubilidade em água em relação às fontes tradicionais de elevada solubilidade em água. 


\title{
AGRONOMIC EFFECTIVENESS OF PHOSPHATE FERTILIZERS VARYING IN WATER SOLUBILITY IN SOILS WITH DIFFERENT P FIXATION CAPACITY
}

\author{
Author: JACK FERNANDO SANTOS QUISPE \\ Adviser: Prof. Dr. LUÍS IGNÁCIO PROCHNOW
}

\section{SUMMARY}

The greenhouse experiment was developed from February to march 2004 utilizing a factorial design with five sources of phosphorus, four rates, two soils varying in phosphorus adsorption capacity, two controls with no phosphorus and three replicates. The study was designed to evaluate the effect of the soil phosphorus adsorption capacity in the relative agronomic effectiveness (RAE, \%) of alternative sources of $\mathrm{P}$, varying in water solubility (low grade SSP-LGSSP, magnesium multiphosphate-MFM, Arad phosphate rock-FR, cationic impurity present in triple superphosphate-H14), as compared to the standard with high water solubility (= reagent grade monocalcium phosphate-FMC), in the rates of 12,5; 25,0; 50,0; and 100,0 $\mathrm{mg} \mathrm{kg}^{-1}$ of total P. Soil sub samples were sieved and mixed with the P sources in the powder form, and corn (Zea mays cultivar Sol da Manhã) cultivated for five weeks. The hypothesis tested was that 
the alternative sources would present higher RAE in the soil with higher phosphorus adsorption capacity. The dry matter-yield followed the same trend in both soils with FMC $>$ MFM $=$ H-14 $>$ LGSSP $>$ FR. The RAE did not present a good relation with the water or the neutral ammonium citrate + water solubility of the sources. The RAE of the alternative $\mathrm{P}$ sources was higher in all cases in the soil with higher $\mathrm{P}$ adsorption capacity when utilizing the lower rates of $\mathrm{P}$, what is in agreement with the hypothesis. New studies are suggested, in greenhouse and specially at field conditions, involving, among other variables, situations related to sources (type and size), time, cultivation system and soils. New datasets can lead to better utilization of phosphorus sources varying in water solubility as related to the traditional sources with high water solubility. 


\section{INTRODUÇÃO}

O uso de fertilizantes de elevada solubilidade em água, porém de custo elevado, em solos da região tropical que possuem elevada capacidade de fixação de fósforo leva a grandes perdas deste elemento no que diz respeito à disponibilidade para as plantas cultivadas.

Por ser o fósforo um dos elementos de menor taxa de recuperação imediata pelas plantas é necessária a otimização das fontes fosfáticas, especialmente em solos de elevada capacidade de fixação que são característicos da região tropical.

Embora muitos trabalhos têm sido feitos abordando o tema da avaliação agronômica de fertilizantes fosfatados, não é possível generalizar os dados obtidos nesses experimentos para todas as condições, uma vez que os fatores que determinam a eficiência agronômica são complexos e pouco conhecidos. Neste caso em particular, poucos têm comparado a eficiência agronômica de fosfatos de solubilidade variável em água em situações distintas quanto a capacidade de fixação de fósforo do solo.

A lenta liberação, "slow release”, de fontes pouco solúveis em água, poderá fazer com que estas, em relação aos de elevada solubilidade, possam ser mais eficientes em solos de elevada capacidade de fixação de fósforo.

Uma melhor compreensão destes fatores poderá auxiliar para melhorar o uso de fontes de fósforo e fornecer opções para um adequado manejo destes fertilizantes no sistema solo-planta na região tropical. 


\section{REVISÃO DE LITERATURA}

\subsection{Solos agricultáveis da região tropical}

Por definição geográfica, a região tropical é a parte do mundo situada entre os 23,5 graus norte e sul do equador, e corresponde a 50\% da superfície da terra e contém, aproximadamente, $45 \%$ da população do mundo (Sanchez, 1981).

Segundo Dudal (1979), o ambiente tropical é aquele no qual a temperatura média mensal ao nível do mar não é menor que $18^{\circ} \mathrm{C}$, o que proporciona um enorme potencial de produtividade às culturas.

De acordo com Sanchez e Logan (1992), a distribuição aproximada dos solos no trópico é a seguinte: Oxisolos (833 milhões de ha, aproximadamente 23\%), Ultisolos (749 milhões ha, aproximadamente 20\%), Alfisolos (559 milhões ha, aproximadamente 15\%), Mollisolos (74 milhões ha, aproximadamente 2\%), Entisolos (574 milhões ha, aproximadamente 16\%), Inceptisolos (532 milhões de ha, aproximadamente 14\%), Vertisolos (163 milhões ha, aproximadamente 5\%), Aridisolos (87 milhões de ha, aproximadamente $2 \%$ ), Andisolos (43 milhões ha, aproximadamente 1\%), Histosolos (36 milhões ha, aproximadamente 1\%) e Spodosolos (20 milhões de ha, aproximadamente $1 \%$ ).

$\mathrm{Na}$ América do Sul tropical predominam Oxisolos (636 milhões de ha, aproximadamente 45,3\%) e Ultisolos (268 milhões de ha, aproximadamente 19,1\%) totalizando 64,4\% da área, seguidos de Alfisolos (171 milhões de ha aproximadamente, 12,2\%), Entisolos (121 milhões de ha, aproximadamente 8,6\%), Inceptisolos (115 milhões de ha, aproximadamente 8,2\%), Mollisolos (54 milhões de ha, aproximadamente 3,9\%), Aridisolos (26 milhões de ha, aproximadamente 1,9\%), 
Vertisolos (9 milhões de ha, aproximadamente 0,7\%) e Histosolos (1 milhão de ha, aproximadamente 0,1\%) (Sanchez, 1976).

Os solos da região tropical expressam certa tendência à: (i) elevada intemperização, (ii) lixiviação de bases ( $\mathrm{Si}, \mathrm{Ca}, \mathrm{Mg}$ e $\mathrm{Na}$ ), e (iii) precipitação do $\mathrm{Fe}, \mathrm{Al}$ e $\mathrm{Mn}$ como óxidos, hidróxidos e oxidróxidos de baixa solubilidade (Pratt et al., 1969; Alleoni, 2003). Nesses solos, o fósforo está ligado principalmente aos óxidos de ferro e alumínio (Raij, 2003).

Os solos da região tropical são, geralmente, pobres em fósforo disponível (Jenny, 1961). Sanchez \& Salinas (1981) calcularam que aproximadamente $82 \%$ dos solos agrícolas do trópico são deficientes em fósforo disponível.

Os solos de elevada intemperização tendem a ser mais eletropositivos do que os solos menos intemperizados, e alguns dos seus atributos químicos, como a capacidade de troca catiônica, a saturação por bases e o valor de $\mathrm{pH}$, apresentam valores menores, enquanto outros, como a adsorção aniônica, possuem valores maiores (Melgar et. al., 1992).

Os solos da região do cerrado, os de maior potencial agrícola do Brasil, no geral apresentam: elevada capacidade de fixação de fósforo, deficiência de nutrientes, baixo valor de pH e elevado grau de saturação por alumínio; a fração argila é composta, principalmente, por caulinita, gibsita e óxidos de ferro (Lopes \& Cox, 1977).

Dentre os solos tropicais, os Latossolos apresentam elevado grau de intemperismo e constituem-se num sistema de elevada retenção de fósforo (Novais \& Smyth, 1999).

\subsection{A capacidade de fixação de fósforo dos solos da região tropical}

Há uma grande indefinição para o termo "capacidade de fixação de fósforo". Malavolta (1976), apresenta a seguinte definição: o processo pelo qual os elementos solúveis são transformados em produtos menos solúveis por reações com componentes inorgânicos ou orgânicos, resultando na diminuição da mobilidade e da disponibilidade.

Sanchez \& Uehara (1980) definem os solos de elevada capacidade de fixação de

fósforo como aqueles que precisam de aplicações acima de $200 \mathrm{~kg} \mathrm{ha}^{-1}$ de $\mathrm{P}$ para manter 
um equilíbrio na solução de $0,2 \mathrm{mg} \mathrm{kg}^{-1}$ de P. Buol et al. (1975) classificam estes solos como aqueles que apresentam uma relação sesquióxido/argila $\geq 0,2$. Este critério foi modificado pelo CIAT (International Center of Tropical Agriculture) para a relação: óxidos de ferro livre/argila $>1,5$ e conteúdo de argila maior que $35 \%$. Os autores também estabeleceram os principais grupos de solos fixadores de fósforo da região tropical, dentre os quais encontram-se os Andosolos, Oxisolos, Ultisolos, Alfisolos e Inceptisolos. De acordo com os autores, a fixação de fósforo em solos brasileiros é um fator de grande importância, e recomendam um manejo especial para esses tipos de solos cujo requerimento pode variar de 300 até $1.000 \mathrm{~kg} \mathrm{ha}^{-1}$ de $\mathrm{P}$.

É importante lembrar que nem todos os solos apresentam elevada capacidade de fixação de fósforo. Isto se deve principalmente às variações entre os solos no que diz respeito ao teor e tipo de argila e conteúdo de óxidos de ferro e alumínio livre. Assim, solos com textura arenosa podem não apresentar elevada capacidade de fixação de fósforo, da mesma forma que solos com elevado teor de argila, associado a um baixo teor de óxidos de ferro e alumínio. Nos solos da região tropical, é importante determinar a capacidade de fixação de fósforo, pois é um dos fatores que governa a disponibilidade do elemento na solução do solo, a dissolução de fertilizantes e, conseqüentemente, a absorção pelas culturas (Sanches \& Uehara, 1980).

No caso do Brasil, alguns solos do cerrado podem fixar até $4.000 \mathrm{~kg} \mathrm{ha}^{-1}$ de $\mathrm{P}$ (Ker, 1995). No caso do estado de São Paulo, Rodrigues (1980), em estudo com 100 solos, determinou que a fixação de fósforo pode chegar até $72 \%$ da quantidade aplicada.

Na região de Piracicaba, Thomazi (1988), em estudo com 8 solos, determinou que para os solos com maior capacidade de fixação era necessária a aplicação de $2.015 \mathrm{mg}$ $\mathrm{kg}^{-1}$ de fósforo para anular o processo de fixação.

Cavalcanti \& Mello (1977) determinaram a capacidade de fixação de três Latosolos, dois Podzólicos e um Hidromórfico, concluindo que os Latosolos fixam mais fósforo que os Hidromórficos, e estes fixam mais fósforo que os Podzólicos.

$\mathrm{Na}$ capacidade de fixação do solo estão envolvidas principalmente reações do tipo covalente por troca de ligantes e precipitação (Parfit, 1978), ocorrendo a formação 
rápida de um grande número de compostos após a aplicação de fertilizantes (Sample et al., 1980).

A quantificação da capacidade de fixação tem sido realizada com o uso de isotermas de adsorção, através de métodos que calculam a diferença de concentrações de uma solução padrão de fósforo, antes e após a agitação de uma amostra de solo ( Novais \& Smyth, 1999).

Inúmeras pesquisas têm sido desenvolvidas a fim de determinar os principais fatores que influenciam a capacidade de fixação de fósforo dos solos. Neste sentido, Sanchez \& Uehara (1980) afirmam que estes fatores são a mineralogia das argilas, o conteúdo coloidal amorfo, o teor de alumínio trocável e de matéria orgânica; e os fatores que controlam a concentração ótima na solução são o estádio de desenvolvimento da planta, a espécie vegetal, a textura do solo, o conteúdo de água e a capacidade de fixação de fósforo.

Mello et al. (1985) considera importante a reação do solo, o conteúdo e o tipo de argila, o tempo da reação, a intimidade da mistura terra-fosfato, a temperatura, a saturação do solo em fósforo, a matéria orgânica, e a umidade do solo. O mesmo autor, em outro estudo, considera que para as condições dos solos do estado de São Paulo, os principais fatores que afetam a capacidade de fixação de fosfato são o conteúdo de óxidos hidratados de ferro e alumínio (Mello, 1968).

Fassbender (1969), estudando a capacidade de fixação de 107 solos da América Central, usando correlações múltiplas e simples, determinou que os principais fatores correlacionados eram o valor de $\mathrm{pH}$ e o conteúdo de óxido de ferro, e que eles explicavam o fenômeno de fixação em $82 \%$. A maioria dos solos apresentava uma capacidade de fixação entre 20 e $40 \%$.

Rodrigues (1980), em estudo similar, com base numa análise de regressão múltipla, determinou que as características que mais influenciaram a capacidade de fixação de fósforo dos solos do estado de São Paulo foram: o conteúdo de carbono, o teor de magnésio e alumínio trocável e o conteúdo de argila. No mesmo trabalho, o autor observou que a capacidade de fixação aumentou com a diminuição do valor de $\mathrm{pH}$. Esta afirmação é concordante com a de Bjeong et al. (1967) e Hasseman et al. (1950). Neste 
sentido, Fassbender (1969) observou em seu estudo que a capacidade de fixação aumenta aproximadamente $6,1 \%$ para cada unidade de $\mathrm{pH}$ reduzida.

Num trabalho pioneiro, Olsen et al. (1957) observaram que solos ácidos fixam fósforo em maior quantidade e com maior energia de ligação que solos alcalinos. Para Parfitt et al. (1975), a intensidade do processo de fixação de fósforo está relacionada com o valor de $\mathrm{pH}$, o qual determina uma maior ou menor competição com grupos hidroxilas pelos orbitais disponíveis dos metais. Isto faz com que a adsorção de fósforo seja por troca de ligantes, sendo o fenômeno conhecido como adsorção específica ou quimisorção (Hignston et al., 1967; Obihara \& Russel, 1972).

Outro fator diretamente relacionado à capacidade de fixação de fósforo é a mineralogia da fração argila. Assim, solos que têm em sua composição minerais cristalinos possuem menor capacidade de fixação quando comparados com outros que possuem minerais mal cristalizados ou amorfos (Fox \& Kamprath, 1970).

Dados de pesquisa mostram que existe relação direta entre o grau de cristalinidade dos minerais do solo e a capacidade de fixação de fósforo (Mulkjadi et al., 1966).

Hasseman et al. (1950), num estudo de capacidade de fixação de fósforo pelos minerais caulinita, montmorillonita e ilita, reportaram uma relação direta da capacidade de fixação de fósforo com a temperatura e a concentração de fósforo, e inversa com o valor de $\mathrm{pH}$.

Trabalhos de pesquisa têm demonstrado que o teor de argila é um fator importante para a determinação da capacidade de fixação de fósforo do solo (Hewall, 1957; Nagarajah, 1968; Klages, 1969; Kuo \& Loste, 1972; Fox \& Kamprath, 1970; Syers, 1971; Galindo, 1972; Leal \& Velloso, 1973; Rodrigues, 1980; Sanchez \& Uehara, 1980).

Hewall (1957) reportou que o fenômeno de fixação está diretamente relacionado com a adsorção de fósforo na superfície das argilas. Colleman (1944) reportou que a maioria do fósforo fixado pelas partículas das frações grosseira e fina foi devido ao capeamento por óxidos de ferro e alumínio livres. 
Syers et al. (1971) reportou correlações positivas entre o teor de argila e o fósforo fixado em solos do sul do Brasil. As mesmas correlações foram encontradas em solos da região central do Brasil por Leal \& Velloso (1973). Tais resultados são concordantes com os obtidos por Juo \& Fox (1977) que encontraram uma correlação positiva entre teores de argila, óxidos ferro e alumino livre, e os teores de fósforo fixado.

Thomazi (1988) concluiu que os fatores principais que contribuem para a fixação de fósforo em solos do município de Piracicaba são o teor de argila e o conteúdo de óxido de ferro livre, e que se pode considerar que o teor de argila é um índice adequado para avaliação da capacidade de fixação de fósforo. Esses resultados são concordantes com os obtidos por Rodrigues (1980) que considera o teor de argila como um dos fatores que mais influenciam a capacidade de fixação de fósforo.

Outro fator que influencia a capacidade de fixação de fósforo é a matéria orgânica, contribuindo para sua diminuição. Isto ocorre porque os radicais orgânicos recobrem as superfícies dos óxidos de $\mathrm{Fe}$ e Al, formando uma barreira física (Fox \& Kamprath 1970).

Relação inversa tem sido encontrada entre o teor de matéria orgânica no solo e a capacidade de fixação (Havlin, 1999).

Olson et al. (1871), trabalhando em solos alcalinos, verificaram que a adição de matéria orgânica incrementou a concentração de fósforo na solução em cerca de três vezes, comparado com os solos que só receberam a aplicação de superfosfato.

Segundo Lindsay \& Moreno (1960), outro fator envolvido na capacidade de fixação é a presença de cátions como cálcio, ferro trivalente, alumínio, magnésio e hidrogênio, que influenciam a disponibilidade de fósforo no solo.

Rodrigues (1980), num estudo sobre os fatores que influenciam a capacidade de fixação de fósforo, encontrou correlação positiva entre o teor de alumínio e a porcentagem de fósforo fixado, não tendo encontrado correlação significativa entre a soma de bases trocáveis e a capacidade de fixação de fósforo. Correlações significativas também foram encontradas por Syers et al. (1971) e Fassbender (1969) entre a capacidade de fixação de fósforo e o teor de alumínio trocável. 


\subsection{Fontes de fósforo}

As fontes naturais de fósforo podem ser encontradas em três tipos de depósitos: guano, fosfatos de alumínio e fosfatos de cálcio; sendo esta última a mais importante (Silva \& Lopes, 1991). Aproximadamente $85 \%$ da produção mundial de fósforo vêm de depósitos sedimentares e 15\% de depósitos magmáticos (Lopes, 2003). No Brasil, cerca de $80 \%$ das jazidas de fosfatos naturais são de origem ígnea, com presença acentuada de rocha carbonatítica e minerais micáceos, com baixo teor de $\mathrm{P}_{2} \mathrm{O}_{5}$.

Segundo Lopes (2003), os recursos mundiais totais em 163 bilhões de toneladas, o que significa 1.200 anos de suprimento nas taxas atuais de consumo. As reservas nacionais de rocha fosfática atingem 2,27 bilhões de toneladas de minério, contendo 222 milhões de toneladas de $\mathrm{P}_{2} \mathrm{O}_{5}$, concentradas principalmente nos estados de Minas Gerais, Santa Catarina, São Paulo e Goiás, sendo, a maioria relacionada a ambienteis geológicos vulcânicos (Brasil, 2004a).

No Brasil podem-se encontrar depósitos de origem ígnea que são depósitos relacionados a carbonatitos dos complexos de Araxá/Tapira (MG), Catalão/Ouvidor (GO), Jacupiranga/Cajati (SP) e o complexo alcalino carbonatítico de Mairicuru (MA), ainda em estudo, e também depósitos de origem sedimentar em estados do Nordeste, como Pernambuco, e no estado de Minas Gerais.

Segundo León et al. (1986), as rochas fosfáticas podem ser classificadas como rochas de reatividade elevada, média, baixa e muito baixa. Por exemplo, o fosfato de Arad é considerado, de acordo com esta classificação, como fosfato de rocha de elevada reatividade, com elevado potencial agronômico. O fosfato de Arad é uma das principais fontes de fosfato natural para o Brasil. No triênio 1999-2001, mais de 80\% da matéria prima (rocha fosfática) vieram de Israel, Marrocos, Tunísia, Togo e Argélia (ANDA, 2003).

As rochas fosfáticas são classificadas de acordo com Lehr (1980) como: (i) "premium grade", (ii) "non premium grade" e (iii) "marginal grade". Os materiais "premium grade" são considerados aqueles que possuem no mínimo $31 \%$ de $\mathrm{P}_{2} \mathrm{O}_{5}$, e teores de cálcio, ferro+alumínio, magnésio e carbonatos livres menores que 29, 3, 0,2 e 
$0,2 \%$, respectivamente, bem como o teor de resíduos insolúveis entre 10 e $15 \%$ em massa. Os materiais "non premium grade" são aqueles onde o teor de $\mathrm{P}_{2} \mathrm{O}_{5}$ é menor que $31 \%$, e apresentam maior teor de impurezas. Os materiais "marginal grade" apresentam um teor de $\mathrm{P}_{2} \mathrm{O}_{5}$ menor que $14 \%$ (68 BPL).

Entre as principais fontes de $\mathrm{P}$ produzidas pela indústria de fertilizantes no Brasil, encontramos as seguintes: (i) fosfatos naturais; (ii) fofatos acidulados, (iii) termofosfatos. Segundo Silveira (2000), os principais fosfatos totalmente acidulados são o superfosfato simples e o superfosfato triplo obtidos pela reação da rocha fosfática com os ácidos sulfúrico e fosfórico, respectivamente, de acordo com as seguintes reações:

(i) $\mathrm{CaF}_{2} \cdot 3 \mathrm{Ca}_{3}\left(\mathrm{PO}_{4}\right)+7 \mathrm{H}_{2} \mathrm{SO}_{4}+3 \mathrm{H}_{2} \mathrm{O} \Rightarrow 3 \mathrm{Ca}\left(\mathrm{H}_{2} \mathrm{PO}_{4}\right)_{2} \cdot \mathrm{H}_{2} \mathrm{O}+7 \mathrm{CaSO}_{4}+2 \mathrm{HF}$

(ii) $\mathrm{CaF}_{2} \cdot 3 \mathrm{Ca}_{3}\left(\mathrm{PO}_{4}\right)_{2}+12 \mathrm{H}_{3} \mathrm{PO}_{4}+9 \mathrm{H}_{2} \mathrm{O} \Rightarrow 9 \mathrm{Ca}\left(\mathrm{H}_{2} \mathrm{PO}_{4}\right)_{2} \cdot \mathrm{H}_{2} \mathrm{O}+\mathrm{CaF}_{2}$

O superfosfato simples pertence ao grupo dos fertilizantes totalmente acidulados. A garantia dos fertilizantes totalmente acidulados é feita com base no teor de $\mathrm{P}_{2} \mathrm{O}_{5}$ solúvel em solução de citrato neutro de amônio + água e em água, e exige elevada solubilidade em água. (84 a 92\% solúveis em água) (Prochnow, 1996).

Atualmente, o principal objetivo da indústria de fertilizantes é produzir fertilizantes fosfatados totalmente acidulados com elevada solubilidade em $\mathrm{CNA}+\mathrm{H}_{2} \mathrm{O}$ e $\mathrm{H}_{2} \mathrm{O}$, tal como especificado pela legislação (Prochnow, 2003).

A avaliação de uma fonte de fósforo com extratores tem como objetivo determinar o potencial agronômico dos fertilizantes. A solubilidade das fontes em extratores químicos exprime seu significado quando correlacionada com a eficiência agronômica. Porém, essas metodologias não consideram a eficiência agronômica de forma direta, nem as formas do fósforo no fertilizante (Alcarde \& Prochnow, 2003).

De acordo com Raij (1991) a caracterização de fontes no Brasil têm sido feita mediante determinações do teor de $\mathrm{P}_{2} \mathrm{O}_{5}$ total, $\mathrm{P}_{2} \mathrm{O}_{5}$ solúvel em $\mathrm{CNA}+\mathrm{H}_{2} \mathrm{O}, \mathrm{P}_{2} \mathrm{O}_{5}$ solúvel em ácido cítrico a $2 \%$ e $\mathrm{P}_{2} \mathrm{O}_{5}$ solúvel em água. 
Ácidos fortes, como $\mathrm{HCl}, \mathrm{HNO}_{3}, \mathrm{H}_{2} \mathrm{SO}_{4}$ e $\mathrm{HClO}_{4}$, têm sido utilizados na avaliação do teor de $\mathrm{P}_{2} \mathrm{O}_{5}$ total. $\mathrm{A}$ extração em solução neutra de citrato de amônio (CNA) tem como objetivo avaliar o fósforo disponível em curto prazo contido nas formas não solúveis em água. Esta extração tem como desvantagem super estimar a solubilização de fosfatos de ferro e alumínio. A determinação dos teores de fósforo pelo método do ácido cítrico a $2 \%$ é usada para avaliar o fósforo disponível de fosfatos pouco solúveis em água como a rocha fosfática. Esta determinação tem se mostrado agronomicamente eficiente. (Alcarde \& Prochnow, 2003).

A eficiência agronômica de fontes fosfáticas segundo Chien \& Menon (1995), é afetada por: o (i) tipo da fonte, (ii) propriedades do solo, (iii) práticas de manejo e a (iv) espécie vegetal. Para Novais \& Smyth (1999) a solubilização de fosfatos é principalmente função das propriedades do solo (acidez e dreno) e da planta, e para Khasawneh \& Doll (1978), os fatores que afetam a eficiência agronômica são: (i) reatividade da fonte, (ii) tamanho de partículas, (iii) $\mathrm{pH}$ do solo, (iv) teor de cálcio e fósforo, (v) textura, (vi) eficiência de absorção pelas plantas e (vii) teor de matéria orgânica.

\subsection{Eficiência agronômica dos fertilizantes fosfatados em solos de elevada capacidade de fixação de fósforo}

Embora a capacidade de fixação e a eficiência agronômica de fosfatos sejam assuntos amplamente discutidos na literatura, a eficiência agronômica relativa de fontes de $\mathrm{P}$ de baixa solubilidade em água, em relação a fontes de alta solubilidade, em solos de elevada capacidade de fixação é pouco estudada.

Nos últimos anos, a aplicação direta de fontes de baixa solubilidade em água tem surgido como uma alternativa de menor custo, o que favoreceu o aumento do seu uso no Brasil (Brasil, 2004b).

Estudos têm demonstrado que a capacidade de fixação tem influência direta sobre a eficiência agronômica de fontes de $\mathrm{P}$, e alguns deles indicam que o aumento da 
capacidade de fixação reduz a eficiência agronômica relativa das fontes (Hammond \& Leon, 1983; Hammond et al., 1986; Butegwa et al., 1996; Flores et al., 2001).

Hamond \& León (1983) mostraram que a eficiência agronômica relativa (EAR) da rocha fosfática Bayobar finamente moída (elevada reatividade e baixa solubilidade em água), em relação ao padrão granulado (superfosfato triplo), é maior em Oxisolos, com capacidade de fixação na faixa de 20 a 30\% (eficiência agronômica relativa na faixa de 107 a $115 \%$ ), e em Ultisolos, com capacidade de fixação na faixa de 32 a $34 \%$ (eficiência agronômica relativa na faixa de 93 a 106 \%), do que em Andosolos com capacidade de fixação na faixa de 41 a 72 \% (eficiência agronômica relativa na faixa de 59 a 88 \%). Esse resultado mostra uma tendência de diminuição da EAR com o aumento da capacidade de fixação.

Hammond et al. (1986) conduziram um experimento em um solo cuja capacidade de fixação foi induzida pela adição de um gel de ferro, a fim de determinar se o incremento da capacidade de fixação do solo influenciava a disponibilidade de $\mathrm{P}$ proveniente de uma fonte pouco solúvel (rocha fosfática Bayobar) no mesmo grau que uma fonte de elevada solubilidade (superfosfato triplo). $\mathrm{O} \mathrm{pH}$ do solo foi mantido próximo a 4,9 ( $\left.\mathrm{pH} \mathrm{H}_{2} \mathrm{O}\right)$ e o diâmetro das partículas de uma fonte foi diferente do da outra. Os autores encontraram que a resposta das plantas ao fósforo proveniente das duas fontes avaliadas foi menor com o aumento da capacidade de fixação, sendo esse efeito negativo maior onde se utilizou a fonte de baixa solubilidade. Os autores concluem que a eficiência agronômica de rocha fosfática de Bayobar diminui mais rapidamente do que a do superfosfato triplo com o aumento da capacidade de fixação de fósforo; o valor médio da EAR foi de $72 \%$.

Butegwa et al. (1996), num estudo com a cultura do milho e dois tipos de solo (textura média e arenosa), compararam o efeito do aumento da capacidade de fixação sobre a eficiência agronômica relativa de três fosfatos (CTSP, CPAPR e PRC ${ }^{1}$ ) derivados de rocha de baixa reatividade variando em solubilidade em água (de 0 a 163,1 $\mathrm{g} \mathrm{kg}^{-1}$ ), e com diâmetros de partícula diferentes. A capacidade de fixação foi ajustada

\footnotetext{
1 Fontes: CTSP, concentrado fosfático de Sukulu Hills compactado com superfosfato triplo (50:50); CPAPR, concentrado fosfático de Sukulu Hills parcialmente acidulado (50\%); PRC, concentrado fosfático de Sukullu Hills.
} 
com um gel de ferro para o solo arenoso de 4 a $14 \%$, e para o solo de textura média de 37 a $61 \%$, mantendo-se o $\mathrm{pH}$ do solo perto de 6,0 $\left(\mathrm{pH} \mathrm{H}_{2} \mathrm{O}\right)$ para ambos os solos. Os resultados mostraram que a EAR, em relação ao superfosfato triplo, decresceu com o aumento da capacidade de fixação, observando-se valores maiores de EAR para as fontes de maior solubilidade em água. No solo de textura média a EAR das fontes mudou de 89, 74 e 0 \% (CTSP, CPAPR e PRC, respectivamente) no solo natural, para 74, 31 e 0,2 \% (idem) no solo com capacidade de fixação induzida. No caso do solo de textura arenosa a EAR mudou de 103, 76 e $7 \%$ (CTSP, CPAPR e PRC, respectivamente) no solo natural, para 89, 69 e $5 \%$ (idem) no solo com capacidade de fixação induzida.

Flores et al. (2001) realizaram um experimento avaliando a resposta de quatro cultivares de triticale e uma de trigo a duas fontes de fósforo em dois solos com capacidades de fixação distintas: um Andosolo e um Phaeozem, 75,5 e 10 \%, respectivamente. Os dados obtidos sugerem que a capacidade de fixação promove um efeito negativo na eficiência agronômica com o aumento da capacidade de fixação para todos os cultivares.

Como visto, sob determinadas condições, não existe um aumento da eficiência agronômica relativa com o incremento da capacidade de fixação de fósforo (Hamond \& León, 1983; Hammond et al., 1986; Butegwwa et al., 1996). Contrariamente, outros trabalhos parecem indicar que a eficiência agronômica relativa aumenta com o incremento da capacidade de fixação.

Nuñes (1984) sugeriu que a EAR das rochas fosfáticas (em relação ao superfofato triplo) é mais elevada em solos de elevada capacidade de fixação, quando comparada com solos de baixa capacidade de fixação de fósforo. Isto seria devido à hipótese de que a lenta liberação de $\mathrm{P}$ da rocha aumenta a absorção de $\mathrm{P}$ pelas plantas.

Chien \& Hammond (1989) realizaram um experimento em casa de vegetação com seis solos de capacidade de fixação diferentes (na faixa de 6 a 56 \%), comparando o efeito da capacidade de fixação sobre a eficiência agronômica relativa de um fosfato de rocha parcialmente acidulado (50\% de acidulação) cujo padrão de comparação foi um fosfato de elevada solubilidade em água (superfosfato simples). Os autores concluíram 
que a rocha fosfática parcialmente acidulada foi tão eficiente quanto a fonte solúvel em condições de acidez e elevada capacidade de fixação de fósforo, tendo havido um aumento da EAR com o incremento da capacidade de fixação. Os valores da EAR variaram de 55 a 84 \%, em relação ao padrão, para a massa seca e a absorção de fósforo, respectivamente, no solo com menor capacidade de fixação (5,6 \%), e na faixa de 123 a $133 \%$ no solo com maior capacidade de fixação $(56,1 \%)$.

Chien (2001) sugere que a eficiência agronômica de fosfatos parcialmente acidulados (40-50\%) é próxima da obtida com superfosfato simples ou superfosfato triplo em algumas culturas e solos tropicais de elevada capacidade de fixação.

Os dados apresentados nos experimentos anteriores mostram que existem diferenças no que diz respeito a: (i) tipo de padrão, (ii) diâmetro de partícula das fontes, (iii) atributos químicos e físicos do solo e (iv) tipo de fonte testada, o que faz difícil obter uma conclusão definitiva.

A fim de explicar por que a eficiência agronômica de fontes de baixa solubilidade em água decresce mais rapidamente do que a de fontes solúveis com o aumento da capacidade de fixação, Hammnond et al. (1986) têm sugerido que isto é devido ao reduzido desenvolvimento das raízes, causado pelo pobre suprimento de fósforo nos estádios iniciais do crescimento da planta. Smith \& Sanchez (1982) têm observado que a capacidade de fixação favorece a dissolução de rocha fosfática sem que isto signifique, necessariamente, um aumento da eficiência por causa da dissolução.

Para eliminar alguns dos fatores que limitam a eficiência agronômica de fertilizantes, tais como a acidez, o baixo suprimento de cálcio e o alto teor de alumínio do solo, a calagem surge como uma alternativa a ser levada em consideração. O emprego da calagem pode possibilitar a determinação do efeito da capacidade de fixação sobre a eficiência agronômica, independentemente das condições de acidez e dos efeitos tóxicos do alumínio que deprimem a produção e influenciam a dissolução de fontes de fósforo.

Em condições ótimas, a capacidade de fixação promoverá a dissolução das fontes fosfatadas, desta forma, poderá haver um equilíbrio nas concentrações de fósforo da solução para um bom suprimento deste nutriente à planta. 
Encontrar alternativas para a aplicação de fertilizantes de baixo custo e baixa solubilidade em água representa, para as condições do Brasil, o melhor uso de recursos, uma possível diminuição do risco de problemas ambientais (eutrofização de mananciais), e a adequação dos elevados custos de produção de fertilizantes a partir de rochas de baixa qualidade.

A melhor compreensão dos fatores que influenciam a eficiência agronômica de fertilizantes em solos de elevada capacidade de fixação poderá auxiliar na melhoria do uso de fontes e fornecer opções para um adequado manejo e uso de fertilizantes no sistema solo-planta na região tropical. Para isso, propõe-se esse estudo, cuja hipótese a ser testada é: fontes de fósforo com menor solubilidade em água, em relação aos de elevada solubilidade, são mais eficientes em solos de elevada capacidade de fixação de fósforo. 


\section{MATERIAL E MÉTODOS}

\subsection{Definição dos solos para o experimento em casa-de-vegetação}

Com a finalidade de selecionar solos distintos quanto à capacidade de fixação de $\mathrm{P}$, e ainda com baixo teor de $\mathrm{P}$ disponível, foram coletadas vinte e uma amostras de diferentes tipos de solos dos estados de São Paulo e Minas Gerais. Estas amostras foram submetidas à análise de rotina, descrita por Raij et al. (2001), e à análise para determinação da capacidade de fixação de fósforo de acordo com o método de Fassbender \& Igue (1967). O método de Fassbender e Igue consiste em agitar 10 gramas de solo com $200 \mathrm{~mL}$ de $\mathrm{KH}_{2} \mathrm{PO}_{4}$, contendo $100 \mathrm{mg} \mathrm{L}^{-1}$ de P por 6 horas, para obter, após filtragem, um extrato onde é feita a determinação do fósforo remanescente, sendo então a quantidade de fósforo adsorvida pelo solo determinada por diferença entre a quantidade de fósforo aplicada e a de fósforo remanescente após agitação. Os resultados destas análises encontram-se na Tabela 1.

Os solos escolhidos foram: Latossolo Vermelho (LV), de textura muito argilosa, de elevada capacidade de fixação (solo 3), e Latossolo Amarelo (LA), de textura média, de baixa capacidade de fixação (solo 10). Estes solos foram escolhidos por apresentarem características adequadas ao estudo e ainda por questões operacionais para coleta. 
Tabela 1. Resultados da análise química das amostras dos solos coletados

\begin{tabular}{|c|c|c|c|c|c|c|c|c|c|c|c|c|c|}
\hline \multirow{2}{*}{$\begin{array}{c}\text { Solos } \\
1\end{array}$} & \multirow{2}{*}{$\begin{array}{c}\begin{array}{c}\text { M.O. } \\
\text { g dm}^{-3}\end{array} \\
21\end{array}$} & \multirow{2}{*}{$\begin{array}{c}\mathbf{p H} \\
\mathbf{C a C l}_{2}\end{array}$} & \multicolumn{2}{|c|}{$\begin{array}{c}S \quad P \\
\text { mg dm }^{-3}\end{array}$} & & Ca & \multicolumn{2}{|c|}{$\mathrm{Mg} \mathrm{H}+\mathrm{Al}$} & \multicolumn{2}{|c|}{$\begin{array}{cc}\text { SB } & \text { CTC } \\
-n^{-3} & --\end{array}$} & $\begin{array}{l}\mathrm{V} \\
\%\end{array}$ & P Fi & xado $^{1}$ \\
\hline & & & 6 & $\sigma_{1}$ & 4,1 & 33 & 10 & 2 & 50,1 & 10,1 & (0) & 6,4 & 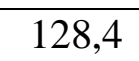 \\
\hline 2 & - & & 67 & 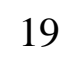 & 2 & 40 & 10 & 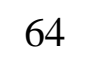 & 2 & & 49 & 10 & \\
\hline 3 & 26 & & 148 & 2 & 1,2 & 10 & & 30 & 2 & 111,2 & 12 & 41 & \\
\hline 4 & r & 3,9 & 61 & 1 & 0,3 & 1 & 5 & 42 & 10,3 & $3 t_{2}$ & 20 & 9,5 & 189,6 \\
\hline 5 & 19 & 4,0 & 68 & 16 & 3,6 & 19 & 8 & 64 & 30,6 & 94 & 32 & 12,9 & 258,7 \\
\hline 6 & 7 & 4,1 & 62 & 1 & 1,1 & 6 & 9 & 47 & 16,1 & 63,1 & 26 & 27,2 & 54 \\
\hline 7 & 7 & 4,2 & 1 & 3 & 0,9 & 6 & 2 & 18 & 8,9 & 26,9 & 33 & 4,4 & 87 \\
\hline 8 & 10 & 4,2 & 5 & 2 & 2,2 & 3 & 3 & 22 & 8,2 & 30,2 & 27 & 2,9 & 57,7 \\
\hline 9 & 10 & 5,0 & 1 & 4 & 1,5 & 62 & 12 & 28 & 75,5 & 103,5 & 73 & 10 & 199,1 \\
\hline 10 & 17 & 4,4 & 28 & 2 & 0,9 & 12 & 5 & 28 & 17,9 & 45,9 & 39 & 9,6 & 192,7 \\
\hline 11 & 5 & 4,4 & 20 & 3 & 2,5 & 26 & 11 & 38 & 39,5 & 77,5 & 51 & 22 & 440,1 \\
\hline 12 & 8 & 3,6 & 18 & 2 & 1,5 & 16 & 6 & 80 & 23,5 & 103,6 & 23 & 10,7 & 213,1 \\
\hline 13 & 3 & * & 8 & * & 5,8 & 40 & 17 & 30 & 62,8 & 92,8 & 68 & 28,1 & 56 \\
\hline 14 & r & 1 & * & 5 & 1 & 3 & 2 & $5 c$ & 6,0 & 65 & 9 & 20,6 & 41 \\
\hline 15 & 44 & * & * & * & 3,6 & 74 & 28 & 50 & 105,6 & ,6 & 63 & 30,1 & 602,7 \\
\hline 16 & 5 & & * & 5 & 1,2 & 4 & 1 & 40 & 6,2 & 46,2 & 13 & 1 & \\
\hline 17 & 34 & 4,1 & * & 6 & 0,9 & 3 & 2 & 66 & 5,9 & 71,9 & 8 & 14,8 & 296,4 \\
\hline Ic & -0 & 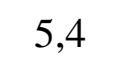 & * & 122 & 5,2 & 97 & 22 & 44 & 24,2 & 168,2 & 74 & 9,8 & , \\
\hline 19 & 5 & 4,3 & * & 4 & 0,1 & 1 & 1 & 4 & 2 , & 45,1 & 5 & 7,1 & 142,5 \\
\hline 20 & 24 & 3,7 & * & 9 & 0,7 & 1 & 1 & 58 & 2,7 & 60,7 & 4 & 13,7 & 274,4 \\
\hline 21 & 5 & 5,4 & * & 9 & 0,7 & 4 & 2 & 25 & 6,7 & 31,7 & 21 & 4,9 & 98,5 \\
\hline
\end{tabular}




\subsection{Caracterização dos solos utilizados no experimento em casa-de-vegetação}

Após a seleção, realizou-se a coleta de amostras dos solos no município de Piracicaba em quantidade suficiente para a montagem do experimento. A coleta das amostras foi realizada à profundidade de 0,4-0,6 m no Latossolo Vermelho (LV), e de 00,2 m no Latossolo Amarelo (LA), em função de essas camadas apresentarem as características desejadas para o estudo. Foram aplicadas quantidades de calcário necessárias para atingir 70 \% da saturação por bases, correspondendo a 12 e 2,5 g de calcário dolomítico (PRNT = 76,41 \%; $\mathrm{CaO}=30,80 \%$; $\mathrm{MgO}=17,73 \%$; RE = 77,11 \%) por vaso, para o LV e LA, respectivamente. Amostras de solo, após a incubação por 20 dias com calcário, foram submetidas à: (i) nova análise de rotina e de determinação da capacidade de fixação de fósforo (Tabela 2) pelos mesmos métodos anteriormente citados; (ii) isotermas de adsorção de fosfato pelo método descrito por Casagrande \& Camargo (1997), que consistiu na agitação de 2,5 g de solo com uma solução de $\mathrm{KH}_{2} \mathrm{PO}_{4}$,

cuja concentração variou de 0 a $1200 \mathrm{mg} \mathrm{L}^{-1}$, por 24 horas em agitador horizontal com 120 movimentos por minuto (Tabela 3); (iii) análise dos teores de ferro livre ou cristalino $\left(\mathrm{Fe}_{\mathrm{DCB}}\right)$ pelo método do ditionito-citrato-bicarbonato (DCB) e teores de ferro mal cristalizado ou pouco cristalino (FexA $\mathrm{F}_{\mathrm{OXA}}$ com extração por solução ácida de oxalato de amônio, na ausência de luz, conforme metodologia descrita por Loeppert \& Inskeep (1996) (Tabela 4); e (iv) difração de raios-x de acordo com a metodologia proposta por Jackson (1969) (dados não incluídos).

As amostras foram ainda caracterizadas quanto a granulometria (Embrapa, 1997), apresentando: 73, 13 e 14 e 20, 6 e 74 \% de argila, silte e areia, respectivamente, para o solo LV e LA, respectivamente, o que está em concordância com os valores de capacidade de fixação de P. 
Tabela 2. Resultados da análise química das amostras dos dois solos selecionados, após a incubação

\begin{tabular}{|c|c|c|c|c|c|c|c|c|c|c|c|c|}
\hline Solos $^{1}$ & $\begin{array}{l}\text { M.O. } \\
\text { g dm}^{-3}\end{array}$ & $\begin{array}{c}\mathrm{pH} \\
\mathrm{CaCl}_{2}\end{array}$ & $\begin{array}{l}S^{2} \quad P \\
\mathrm{mg} \mathrm{dm}^{-3}\end{array}$ & $\mathbf{K}$ & Ca & $\begin{array}{c}\mathbf{M g} \\
\mathrm{m}\end{array}$ & I & SB & CTC & $\begin{array}{l}\mathrm{V} \\
\%\end{array}$ & $\begin{array}{l}\text { P Fi } \\
\%\end{array}$ & $\begin{array}{l}\text { ixado } \\
\text { mg kg }^{-1}\end{array}$ \\
\hline LV & 20 & 5,3 & 2 & 2,3 & 33 & 27 & 31 & 62,3 & 93,3 & 67 & 36,5 & 731 \\
\hline LA & 15 & 5,4 & 2 & 1,3 & 18 & 12 & 16 & 31,3 & 47,3 & 66 & 9,3 & 186 \\
\hline
\end{tabular}

${ }^{1}$ LV, Latossolo Vermelho; LA, Latossolo Amarelo

${ }^{2}$ Elemento não analisado

${ }^{3}$ Metodologia descrita por Fassbender e Igue (1967)

Tabela 3. Resultados da Isoterma de Langmuir para adsorção de fósforo nos solos selecionados

\begin{tabular}{ccccc}
\hline Solos $^{1}$ & Equação de regressão & CMAF $^{2}$ & $\mathbf{R}^{2}$ & Teor de argila \\
\hline & & mg kg $^{-1}$ & & $\%$ \\
LV & $Y=1,19+0,4689 X$ & 2132 & 0,91 & 73 \\
LA & $Y=12,156+2,7626 X$ & 362 & 0,85 & 20 \\
\hline
\end{tabular}

${ }^{1}$ LV: Latossolo Vermelho, LA: Latossolo Amarelo

${ }^{2}$ CMAF: capacidade máxima de adsorção de fósforo, obtida com a isoterma de Langmuir

Tabela 4. Resultados das análises mineralógicas das amostras dos dois solos selecionados para o experimento em casa-de-vegetação

\begin{tabular}{ccccc}
\hline Solos $^{1}$ & \multicolumn{2}{c}{$\mathbf{F e}_{2} \mathbf{O}_{3} \mathbf{O X A L A T O}^{2}$} & \multicolumn{2}{c}{$\mathbf{F e}_{2} \mathbf{O}_{3} \mathbf{D C B}^{3}$} \\
\hline & $\%$ & $\mathrm{~g} \mathrm{~kg}^{-1}$ & $\%$ & $\mathrm{~g} \mathrm{~kg}^{-1}$ \\
$\mathrm{LV}$ & 1,7 & 17,4 & 5,70 & 57,0 \\
$\mathrm{LA}$ & 0,5 & 5,1 & 1,84 & 18,4 \\
\hline
\end{tabular}

${ }^{1}$ LV, Latossolo Vermelho; LA, Latossolo Amarelo

${ }^{2}$ Ferro pouco cristalino determinado com solução ácida de oxalato de amônio

${ }^{3}$ Ferro livre determinado pelo método do ditionito-citrato-bicarbonato 
Os resultados das análises químicas de rotina, da capacidade de fixação de fósforo pelo método de Fassbender \& Igue (Tabela 2) e das isotermas de adsorção de fosfato (Tabela 3) confirmaram tratar-se de solos adequados para o experimento em casa-de-vegetação (ambos com baixo teor de $\mathrm{P}$ disponível e distintos quanto à capacidade de fixação de $\mathrm{P}$ ). Os resultados das análises de raios $\mathrm{x}$ não permitiram explicar as diferenças quanto à capacidade de fixação de P (difratogramas semelhantes; dados não incluídos) entre os dois solos, porém os resultados dos teores de ferro apontam para quantidades mais elevadas no LV, o que está de acordo com os números obtidos para a capacidade de fixação de P.

\subsection{Fontes de fósforo utilizadas no experimento}

Nesse estudo foram utilizadas cinco amostras de fosfatos que apresentam diferenças quanto à solubilidade em água. As fontes estudadas foram: fosfato monocálcico p.a. (FMC), low-grade SSP - "superfosfato simples” (LGSSP), multifosfato magnesiano (MFM), fosfato de rocha de Arad (FR) e a impureza catiônica do tipo Fe-Al-P (H-14) que foi preparada em condições de laboratório (Biassioli, 2003).

O low grade -SSP foi obtido pela acidulação de concentrado apatítico tipo reflotável da rocha de Araxá. Uma das características deste SSP é a de possuir fração insolúvel em água dominada por compostos do tipo Fe-Al-P. Outros detalhes sobre a produção e características deste SSP podem ser encontrados em Prochnow (2003). A impureza $\mathrm{H}-14$, com fórmula química igual a $\mathrm{Fe}_{3} \mathrm{KH}_{14}\left(\mathrm{PO}_{4}\right)_{4} \cdot 4 \mathrm{H}_{2} \mathrm{O}$, é parte integrante da fração insolúvel em água de superfosfatos triplos. Foram determinados os teores de $\mathrm{P}_{2} \mathrm{O}_{5}$ total, $\mathrm{P}_{2} \mathrm{O}_{5}$ solúvel em citrato neutro de amônio mais água $\left(\mathrm{CNA}+\mathrm{H}_{2} \mathrm{O}\right), \mathrm{P}_{2} \mathrm{O}_{5}$ solúvel em ácido cítrico a 2\%, na relação fertilizante:extrator de 1:100, e $\mathrm{P}_{2} \mathrm{O}_{5}$ solúvel em água, de acordo com Brasil (1982) (Tabela 5). 
Tabela 5. Teores de $\mathrm{P}_{2} \mathrm{O}_{5}$ total, solúvel em $\mathrm{CNA}+\mathrm{H}_{2} \mathrm{O}$, solúvel em água e solúvel em ácido cítrico a $2 \%$, e porcentagem da fração solúvel em $\mathrm{H}_{2} \mathrm{O}$ na fração solúvel em $\mathrm{CNA}+\mathrm{H}_{2} \mathrm{O}$ (fi), das fontes de $\mathrm{P}$ utilizadas no experimento

\begin{tabular}{|c|c|c|c|c|c|}
\hline \multirow{2}{*}{ Fonte de $\mathbf{P}^{2}$} & \multicolumn{5}{|c|}{ Teor de $\mathrm{P}_{2} \mathrm{O}_{5}{ }^{1}$} \\
\hline & Total & $\begin{array}{l}\text { Solúvel em } \\
\mathrm{CNA}+\mathrm{H}_{2} \mathrm{O}\end{array}$ & $\begin{array}{c}\text { Solúvel em } \\
\mathrm{H}_{2} \mathrm{O} \\
\end{array}$ & $\begin{array}{l}\text { Solúvel em } \\
\text { Ac. Cítrico }\end{array}$ & $\mathbf{F i}^{3}$ \\
\hline & \multicolumn{5}{|c|}{ 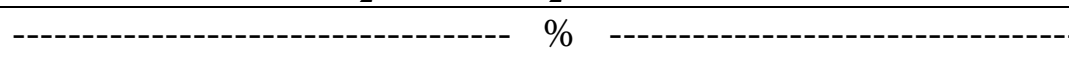 } \\
\hline FMC & 55,8 & 55,3 & 54,2 & 54,6 & 98 \\
\hline LGSSP & 20,0 & 15,4 & 7,9 & $*$ & 51 \\
\hline MFM & 19,1 & 15,1 & 5,2 & 17,7 & 34 \\
\hline ARAD & 34,3 & 5,22 & 0,6 & 12,5 & 11 \\
\hline H-14 & 23,2 & 22,2 & 1,0 & $*$ & 4,5 \\
\hline
\end{tabular}

${ }^{1}$ Metodologia descrita em Brasil (1982)

2 FMC: fosfato monocálcico; LGSSP: low-grade SSP - "superfosfato simples” com baixa solubilidade em água; MFM: multifosfato magnesiano; ARAD: fosfato de rocha de Arad; H-14: impureza catiônica do tipo H-14

${ }^{3}$ (P solúvel em água / P solúvel em CNA+água)X100

* Dados não disponíveis

\subsection{Avaliação da eficiência agronômica das fontes de fósforo em condições de casa- de-vegetação}

Foi conduzido um experimento no período de 5 de fevereiro a 20 de março de 2004 na casa de vegetação do Departamento de Solos e Nutrição de Plantas da ESALQ/USP.

Vasos plásticos com capacidade de 3,5 kg foram preenchidos com $3 \mathrm{~kg}$ de terra após incubação com o calcário, seguindo-se a aplicação das fontes de fósforo na forma de pó finamente moído, quando o caso, nas doses de 12,5; 25; 50 e $100 \mathrm{mg} \mathrm{kg}^{-1}$ de $\mathrm{P}$ total, segundo o delineamento experimental que consta da Tabela 1 do apêndice. A adubação básica consistiu na aplicação de $200 \mathrm{mg} \mathrm{kg}^{-1}$ de $\mathrm{N}$, como uréia, e $200 \mathrm{mg} \mathrm{kg}^{-1}$ de $\mathrm{K}$, como KCl. Uma solução contendo magnésio, enxofre e micronutrientes foi 
adicionada para suprir 96, 135, 5, 11, 8, 2 e 0,2 $\mathrm{mg} \mathrm{kg}^{-1}$, respectivamente, de $\mathrm{Mg}, \mathrm{S}, \mathrm{Cu}$, Zn, Mn, B e Mo.

Oito sementes de milho (Zea mays L.), cultivar Sol da manhã, foram semeadas nos vasos que posteriormente foram irrigados. Para o experimento a umidade do solo foi mantida constante a $70 \%$ da capacidade de retenção de água, tendo sido esta determinada pela metodologia do torrão separado pela frente de molhamento, proposta por Costa (1983).

Após 10 dias da semeadura foi feito o desbaste para duas plantas por vaso e realizou-se a primeira adubação de cobertura que constou de $\mathrm{N}$ e S nas doses de 100 e 50

$\mathrm{mg} \mathrm{kg}{ }^{-1}$, respectivamente. A segunda adubação de cobertura após 30 dias constou da aplicação de $\mathrm{N}$ como uréia em solução, na dose de $150 \mathrm{mg} \mathrm{kg}{ }^{-1}$.

Os parâmetros avaliados neste estudo foram: matéria seca produzida e fósforo acumulado na planta. A concentração de fósforo na planta foi obtida mediante digestão nitro perclórica e determinação de fósforo nos extratos por espectrofotometria utilizando a metodologia descrita por Malavolta et al. (1997).

\subsection{Análise estatística}

Foi utilizado o delineamento estatístico de blocos completos ao acaso, com arranjo fatorial de 5 fontes de fósforo, quatro doses, dois tipos de solos, duas testemunhas sem fósforo e três repetições, totalizando 126 unidades experimentais (Tabela 1 do apêndice).

Os dados (Tabelas 2 e 4 do apêndice) foram submetidos à análise de variância. Os parâmetros qualitativos foram submetidos ao teste de comparação de médias por Tuckey, ao nível de 5\% de probabilidade, e os dados quantitativos à análise de regressão, utilizando o pacote estatístico SAS e modelos matemáticos descritos em Prochnow et al. (2003). Estes modelos matemáticos foram os que se seguem: 
Ajuste de resposta em função de doses aplicadas:

$$
\begin{aligned}
Y i & =\beta o+\beta i \mathrm{X}+\varepsilon_{i}, \mathrm{X} \geq 0, \\
Y i & =\beta o+\beta i \ln \mathrm{X}+\varepsilon_{i}, \mathrm{X} \geq 1 \text { ou } \\
\mathrm{Y} i & =\beta o+\beta i \mathrm{X}^{1 / 2}+\varepsilon_{i}, \mathrm{X} \geq 0
\end{aligned}
$$

onde Yi é a produção de matéria seca ou $\mathrm{P}$ acumulado, $\mathrm{X}$ é a dose de $\mathrm{P}$ aplicada, $\beta i$ é o coeficiente angular da regressão para a fonte $i$, $\beta o$ é o ponto comum de intersecção das regressões com o eixo $\mathrm{Y}$, e $\varepsilon_{i}$ o termo de erro para a regressão proposta.

\section{Eficiência agronômica relativa:}

A EAR foi definida como a razão entre a variável resposta (matéria seca ou P acumulado) da fonte e do padrão ou de seus coeficientes angulares:

$$
E A R i=\frac{\beta i}{\beta F M C p a} \times 100
$$

onde $\beta i$ é o valor da variável resposta em determinada dose ou coeficiente angular da regressão para a fonte em estudo e o $\beta F M C p a$ o valor da variável resposta em determinada dose ou coeficiente angular da regressão para a fonte padrão de $\mathrm{P}$ (fosfato monocálcico). A comparação destas razões permite classificar as fontes em relação à fonte padrão de P em termos de eficiência potencial para produzir resposta (Chien et al., 1990). 
Diferença significativa entre duas fontes de P na amplitude de doses testadas:

$$
t=\frac{|\beta \mathrm{i} a-\beta \mathrm{ib}|}{\sqrt{(S E(\beta \mathrm{i} a))^{2}+(S E(\beta \mathrm{i} b))^{2}}}
$$

onde $\beta_{\text {ia }}$ é o coeficiente angular da regressão para a primeira fonte de $\mathrm{P}$ testada, $\beta_{i b} \mathrm{o}$ coeficiente angular da regressão para a segunda fonte, SE ( $\left.\beta_{i a}\right)$ é o erro padrão para $\beta_{i a} \mathrm{e}$ SE $\left(\beta_{i b}\right)$ o erro padrão para a fonte $\beta_{i b}$. 


\section{RESULTADOS E DISCUSSÃO}

A Tabela 6 contém os valores de $\mathrm{F}$ e $\operatorname{Pr}>\mathrm{F}$ para a variável matéria seca produzida, considerando-se as causas de variação: 5 fontes de fósforo, 4 doses, 2 solos e interações possíveis. Houve efeito significativo dos três fatores estudados independentemente e das interações entre os fatores. Os desdobramentos foram realizados considerando-se a interação tripla com análise de cada fator dentro dos demais.

Dos três modelos testados no ajuste de produção de matéria seca das plantas de milho em função de doses aplicadas, o linear foi o que melhor se ajustou $\left(\mathrm{R}^{2}\right.$ igual a 0,97; 0,83 e 0,90 e 0,98; 0,85 e 0,92 para os modelos linear, logarítmico e raiz quadrada, respectivamente, para os solos de elevada e baixa capacidade de fixação). Para a variável $\mathrm{P}$ acumulado o modelo que apresentou o melhor ajuste foi também o linear $\left(\mathrm{R}^{2}\right.$ igual a 0,$96 ; 0,74$ e 0,82 e 0,$97 ; 0,75$ e 0,85 para os modelos linear, logarítmico e raiz quadrada, respectivamente, para os solos de elevada e baixa capacidade de fixação). A Tabela 7 apresenta os coeficientes angulares calculados para cada situação de fonte e solo. Tendo em vista estes valores foram confeccionados os gráficos relacionando matéria seca (dado obtido e ajuste segundo coeficiente angular) e dose de P para cada fonte e solo (Figura 1). 
Tabela 6. Valores de F e coeficiente de variação (C.V.) para a análise da variância dos dados de matéria seca produzida por plantas de milho em função do solo, dose e fonte de fertilizante fosfatado

\begin{tabular}{cccc}
\hline Causa de variação & G.L. & Valor F & Pr $>$ F \\
\hline Bloco & 2 & 0,19 & 0,824 \\
Fonte & 4 & 198,50 & $<0,001$ \\
Dose & 3 & 530,40 & $<0,001$ \\
Solo & 1 & 128,00 & $<0,001$ \\
Fonte x Dose & 12 & 36,62 & $<0,001$ \\
Fonte x Solo & 4 & 14,59 & $<0,001$ \\
Dose x Solo & 3 & 39,93 & $<0,001$ \\
Fonte x Dose x Solo & 12 & 2,62 & 0,005 \\
& & C. V. $=16 \%$ & \\
\hline
\end{tabular}


Tabela 7. Parâmetros estimativos das regressões lineares ajustadas para descrever a relação entre a matéria seca produzida e as doses de P nos solos de elevada e baixa capacidade de fixação de fósforo

\begin{tabular}{|c|c|c|c|}
\hline \multirow{2}{*}{ Fonte de $\mathbf{P}$} & \multirow{2}{*}{ Parâmetro } & \multicolumn{2}{|c|}{ Matéria seca } \\
\hline & & $\mathbf{L V}$ & LA \\
\hline & Bo & $1,35^{* *}$ & $1,180^{* *}$ \\
\hline \multirow[t]{2}{*}{ FMC } & B1 & $0,09727 * *$ & $0,165 * *$ \\
\hline & & $(0,00408)$ & $(0,00494)$ \\
\hline \multirow[t]{2}{*}{ LGSSP } & B2 & $0,01939 * *$ & $0,064 * *$ \\
\hline & & $(0,00408)$ & $(0,00494)$ \\
\hline \multirow[t]{2}{*}{ MFM } & B3 & $0,06967 * *$ & $0,106 * *$ \\
\hline & & $(0,00408)$ & $(0,00494)$ \\
\hline \multirow[t]{2}{*}{ FR } & B4 & $0,00615 \mathrm{~ns}^{1}$ & $0,029 * *$ \\
\hline & & $(0,00408)$ & $(0,00494)$ \\
\hline \multirow[t]{2}{*}{$\mathrm{H}-14$} & B5 & $0,05940 * *$ & $0,102 * *$ \\
\hline & & $(0,00408)$ & $(0,00494)$ \\
\hline Observações & & 63 & 63 \\
\hline
\end{tabular}

A eficiência agronômica relativa baseada nos coeficientes angulares, a qual representa na amplitude das doses testadas a situação comparativa entre uma fonte alternativa e a fonte padrão, encontra-se na Tabela 8. Observa-se que a tendência foi para FMC $>$ MFM $=$ H14 $>$ LGSSP $>$ FR em ambos os solos (Figura 1 e Tabela 8). 

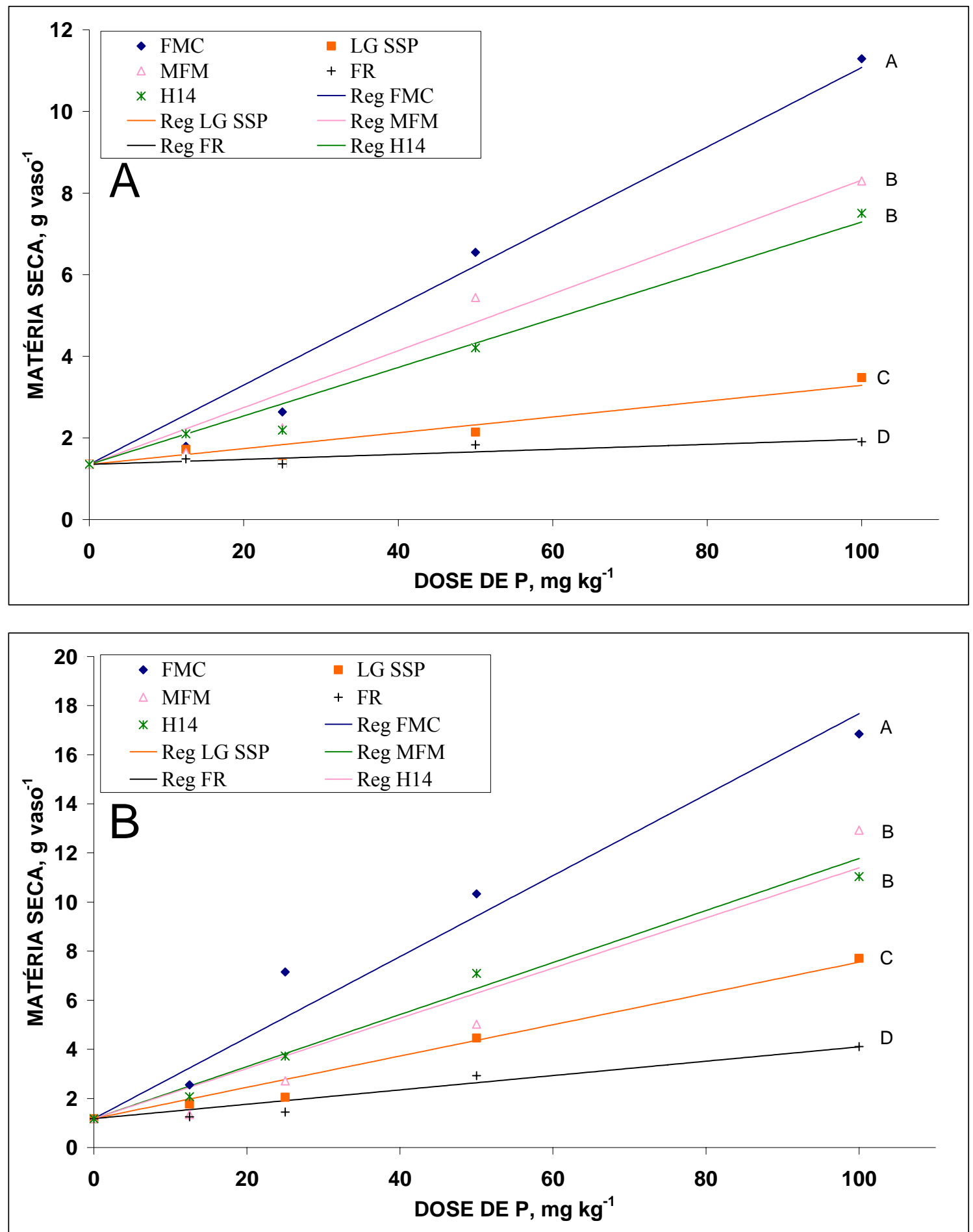

Figura 1 - Efeito das fontes e doses de fósforo na produção de matéria seca de plantas de milho cultivadas em amostras de terra de um solo Latossolo Vermelho (A) e um solo Latossolo Amarelo (B). Modelos seguidos da mesma letra não diferem estatisticamente $(\mathrm{P} \leq 0.01)$ 
Tabela 8. Eficiência agronômica relativa $\left(\mathrm{EAR}^{1}\right.$; \%) das fontes de fósforo em relação ao FMC em solos de elevada (LV) e baixa (LA) capacidade de fixação de fósforo

\begin{tabular}{ccc}
\hline Fonte de $\mathbf{P}$ & Matéria seca & LA \\
\hline FMC & 100 & 100 \\
LGSSP & 20 & 39 \\
MFM & 72 & 64 \\
FR & 6 & 18 \\
H-14 & 61 & 62 \\
\hline${ }^{\operatorname{EAR}=\left(\beta_{i} / \beta_{F M C}\right) \times 100, i=\text { fonte alternativa }}$ &
\end{tabular}

${ }^{1} \operatorname{EAR}=\left(\beta_{i} / \beta_{F M C}\right) \times 100, \mathrm{i}=$ fonte alternativa 
A EAR não guardou relação direta com a solubilidade em água ou em CNA + $\mathrm{H}_{2} \mathrm{O}$ das fontes de fósforo. Um exemplo disto foi que o LGSSP, com solubilidade em CNA $+\mathrm{H}_{2} \mathrm{O}$ similar ao MFM (Tabela 5), apresentou EAR bem menor que o obtido para o MFM. Estes dados confirmam suposição de que materiais contendo frações insolúveis em água, com composição a base de fosfatos de Fe e Al (caso do LGSSP), não são adequadamente avaliados através do extrator $\mathrm{CNA}+\mathrm{H}_{2} \mathrm{O}$. Isto foi discutido em Prochnow et al. (2003), os quais apontam que compostos do tipo Fe-Al-P podem se dissolver em solução de $\mathrm{CNA}+\mathrm{H}_{2} \mathrm{O}$, o que não necessariamente significa que estes estarão disponíveis às plantas no sistema solo.

$\mathrm{Na}$ amplitude de doses testadas não houve tendência clara para qual a situação de capacidade de fixação de fósforo em que a EAR seria maior (Tabela 8). Verifica-se, por exemplo, que o LGSSP teve maior EAR no $\mathrm{LA}^{2}$, enquanto para o MFM ocorreu o contrário. É preciso notar que a EAR relacionada na Tabela 8 representa a média na amplitude das doses testadas. A análise da EAR para cada dose poderia fornecer subsídios para uma interpretação mais adequada dos dados. Assim, na Tabela 9 desdobram-se os efeitos de solo e fonte dentro de cada dose e na Tabela 10 apresenta-se a EAR em cada situação de solo, fonte e dose.

\footnotetext{
${ }^{2}$ As abreviaturas LA e LV, ao longo do texto, referem-se às amostras coletadas do Latossolo Amarelo e Latossolo Vermelho, respectivamente, e utilizadas no experimento em casa-de-vegetação.
} 
Tabela 9. Efeito da capacidade de adsorção de fósforo do solo e fonte de fósforo na matéria seca (gramas) produzida por plantas de milho nas doses 12,$5 ; 25 ; 50$ e $100 \mathrm{mg} \mathrm{kg}^{-1}$ de $\mathrm{P}$ em solos de elevada (LV) e baixa (LA) capacidade de fixação de fósforo

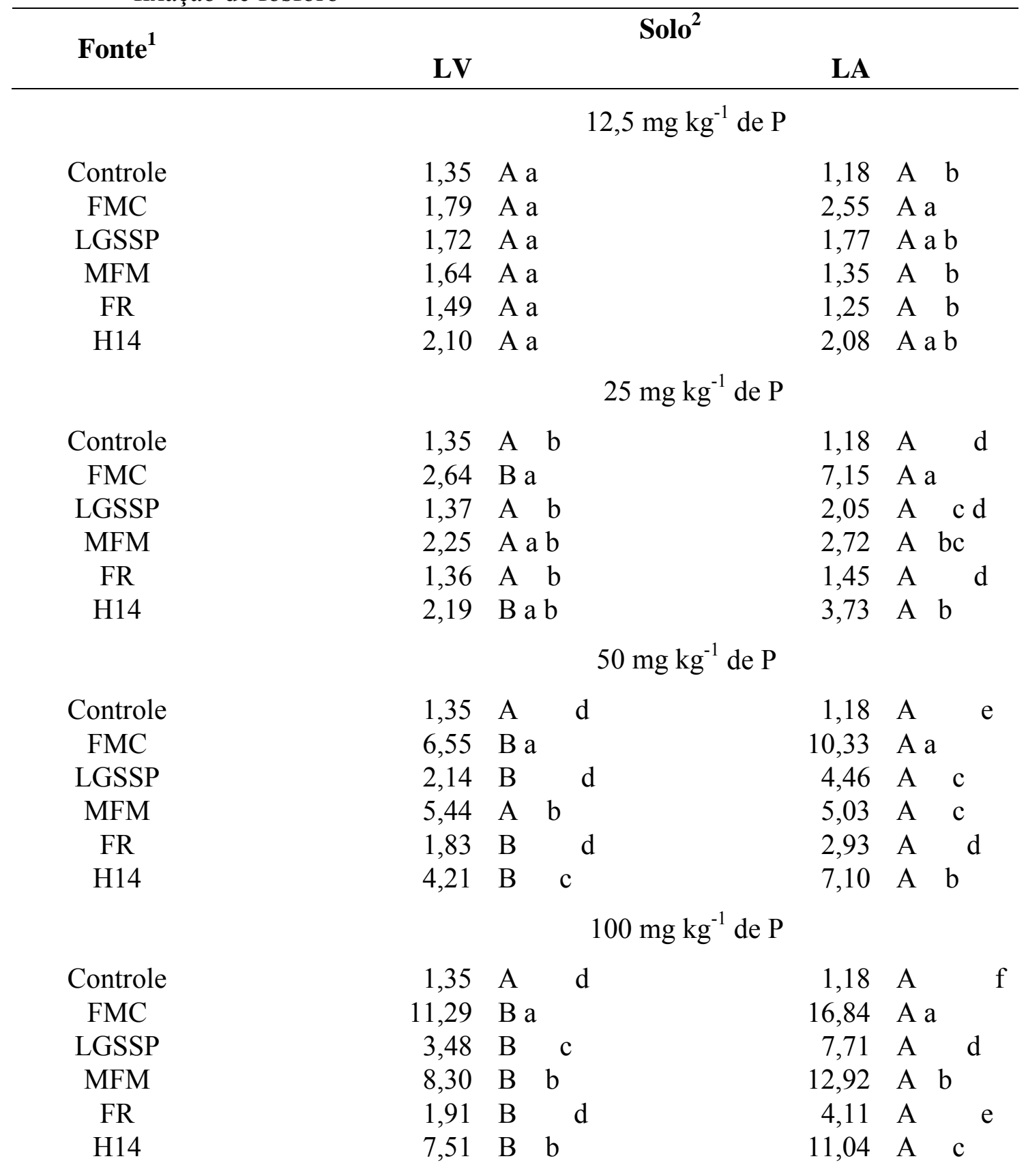

${ }^{1}$ FMC: fosfato monocálcico; LGSSP: low-grade SSP - "superfosfato simples" com baixa solubilidade em água; MFM: multifosfato magnesiano; ARAD: fosfato de rocha de Arad; H-14: impureza catiônica do tipo H-14

${ }^{2}$ LV: Latossolo Vermelho, LA: Latossolo Amarelo 
Tabela 10. Eficiência agronômica relativa para matéria seca das fontes de fósforo em relação ao FMC para plantas de milho, nas doses 12,5;25, 50 e $100 \mathrm{mg} \mathrm{kg}^{-1}$ de $\mathrm{P}$ em solos de elevada (LV) e baixa (LA) capacidade de fixação de fósforo

\begin{tabular}{|c|c|c|}
\hline \multirow{2}{*}{ Fonte $^{1}$} & \multicolumn{2}{|c|}{ Solo $^{2}$} \\
\hline & LV & LA \\
\hline & \multicolumn{2}{|c|}{$12,5 \mathrm{mg} \mathrm{kg}^{-1} \mathrm{de} P$} \\
\hline FMC & 100 & 100 \\
\hline LGSSP & 96 & 69 \\
\hline MFM & 92 & 53 \\
\hline FR & 83 & 49 \\
\hline \multirow[t]{2}{*}{ H14 } & 117 & 81 \\
\hline & \multicolumn{2}{|c|}{$25 \mathrm{mg} \mathrm{kg}^{-1}$ de $\mathrm{P}$} \\
\hline FMC & 100 & 100 \\
\hline LGSSP & 52 & 29 \\
\hline MFM & 85 & 38 \\
\hline FR & 52 & 20 \\
\hline \multirow[t]{2}{*}{ H14 } & 83 & 52 \\
\hline & \multicolumn{2}{|c|}{$50 \mathrm{mg} \mathrm{kg}^{-1}$ de $\mathrm{P}$} \\
\hline FMC & 100 & 100 \\
\hline LGSSP & 33 & 43 \\
\hline MFM & 83 & 49 \\
\hline FR & 28 & 28 \\
\hline \multirow[t]{2}{*}{ H14 } & 64 & 69 \\
\hline & \multicolumn{2}{|c|}{$100 \mathrm{mg} \mathrm{kg}^{-1} \mathrm{de} P$} \\
\hline FMC & 100 & 100 \\
\hline LGSSP & 31 & 46 \\
\hline MFM & 73 & 77 \\
\hline FR & 17 & 24 \\
\hline H14 & 66 & 66 \\
\hline
\end{tabular}

FMC: fosfato monocálcico; LGSSP: low-grade SSP - "superfosfato simples" com baixa solubilidade em água; MFM: multifosfato magnesiano; ARAD: fosfato de rocha de Arad; H-14: impureza catiônica do tipo $\mathrm{H}-14$

${ }^{2}$ LV, Latossolo Vermelho; LA, Latossolo Amarelo 
De forma geral a dose de $12,5 \mathrm{mg} \mathrm{kg}^{-1}$ de $\mathrm{P}$ mostrou-se muita baixa para promover resposta ao fósforo, e assim sendo, excetuando-se alguns casos, não houve diferenças significativas entre solos para cada fonte e fontes para cada solo (Tabela 9). Nas doses mais elevadas a tendência foi para maior produção de matéria seca de milho no LA, sendo que na maioria dos casos ocorreram diferenças significativas. Os dados de matéria seca nas doses mais elevadas (acima de 12,5 $\mathrm{mg} \mathrm{kg}^{-1}$ de P; Tabela 9) revelam a mesma tendência de eficiência das fontes daquela apontada pela análise dos coeficientes angulares ajustados, ou seja, FMC $>$ MFM $=$ H14 $>$ LGSSP $>$ FR $>$ controle.

O cálculo da EAR, tal como apresentado na Tabela 10 (individualizado por dose), acrescenta uma perspectiva interessante em relação ao objetivo do trabalho. Verifica-se que para doses mais baixas de P aplicado (12,5 e $25 \mathrm{mg} \mathrm{kg}^{-1}$ de P) a EAR das fontes alternativas foi, em todos os casos, maior no solo de mais elevada capacidade de fixação de P. Para as duas doses mais elevadas de P, exceção feita ao MFM na dose de $50 \mathrm{mg} \mathrm{kg}^{-1}$, as EARs foram similares nos dois solos. Os dados sugerem, portanto, que fontes de menor solubilidade em água, quando aplicadas em doses relativamente baixas de $\mathrm{P}$, apresentam maior EAR em solos de elevada capacidade de fixação, o que está de acordo com a hipótese do trabalho.

Duas possibilidades, ou a interação de ambas, existem para explicar a maior EAR de fontes menos solúveis em solos de elevada capacidade de fixação de $\mathrm{P}$, em relação aos de baixa: (1) drástica diminuição na disponibilidade de $\mathrm{P}$ das fontes solúveis e (2) maior disponibilidade de $\mathrm{P}$ das fontes menos solúveis devido ao forte efeito de adsorção (dreno de $\mathrm{P}$ para sítios de adsorção facilitariam a solubilização destes fosfatos). A análise dos resultados médios da matéria seca produzida da Tabela 9 permite verificar que neste estudo a possibilidade (1) foi a que prevaleceu. Como exemplo, tem-se a eficiência das fontes na dose $25 \mathrm{mg} \mathrm{kg}^{-1}$ de $\mathrm{P}$, onde todas as fontes alternativas tiveram EAR mais elevada quando aplicadas no LV (Tabela 10). Verifica-se que não houve aumento da produção de matéria seca no LV em relação ao LA quando as fontes alternativas foram aplicadas (Tabela 9). Pelo contrário, no caso do H14 o cultivo sob o LA propiciou produção significativamente maior de matéria seca do que em cultivo sob LV. 
Para o FMC observa-se elevada diminuição na produção de matéria seca quando aplicado no LV em relação ao LA. Isto demonstra que a maior EAR para as fontes alternativas, aplicadas nas doses 12,5 e $25 \mathrm{mg} \mathrm{kg}^{-1}$ de $\mathrm{P}$, no LV, em relação ao LA (Tabela 10), resultou da diminuição drástica da eficiência da fonte solúvel em água, e não a um aumento da eficiência da fonte de baixa solubilidade em água. No sentido de esclarecer melhor a situação alguns números são apresentados. No caso do FMC, na dose de $25 \mathrm{mg} \mathrm{kg}^{-1}$ de $\mathrm{P}$, a produção no LV foi de $37 \%$ da produção obtida no LA. Já para o MFM a produção foi de $83 \%$. Ou seja, a redução é muito mais drástica no caso do FMC do que para as fontes alternativas. Como a EAR é calculada tendo como padrão o FMC, a diminuição drástica da produção de matéria seca com esta fonte levou a uma maior EAR das fontes alternativas no solo de elevada capacidade de fixação de $\mathrm{P}$, ou seja, o LV.

No caso de doses mais elevadas de $\mathrm{P}$ a tendência não é a mesma devido à elevada disponibilidade deste nutriente às plantas no curto intervalo de tempo considerado. É possível que com o passar do tempo, e a conseqüente transformação de formas lábeis para não lábeis, a situação fosse diferente mesmo em doses mais elevadas.

Os dados de $\mathrm{P}$ acumulado foram analisados e organizados nas Tabelas 11 a 15 e Figura 2. A análise e interpretação destes dados permitem verificar as mesmas tendências gerais às apresentadas e discutidas para matéria seca, ou seja: (1) eficiência das fontes na ordem FMC $>$ MFM = H14 $>$ LGSSP $>$ FR, (2) ausência de boa relação entre solubilidade em água, ou em $\mathrm{CNA}+\mathrm{H}_{2} \mathrm{O}$, e EAR, (3) tendência de maior EAR no LV nas doses baixas de $\mathrm{P}$, e (4) diminuição drástica da quantidade de $\mathrm{P}$ acumulado do FMC quando as plantas foram cultivadas no LV. 
Tabela 11. Valores de F e coeficientes de variação (C.V.) para a análise de variância dos dados de o fósforo acumulado por plantas de milho em função do solo, dose e fonte de fertilizante fosfatado

\begin{tabular}{lccc}
\hline Causa de variação & G.L. & Valor $\mathbf{F}$ & Pr $>$ F \\
\hline Bloco & 2 & 0,68 & 0,5220 \\
Fonte & 4 & 211,75 & $<0,0001$ \\
Dose & 3 & 616,83 & $<0,0001$ \\
Solo & 1 & 288,47 & $<0,0001$ \\
Fonte x Dose & 12 & 59,65 & $<0,0001$ \\
Fonte x Solo & 4 & 33,73 & $<0,0001$ \\
Dose x Solo & 3 & 119,21 & $<0,0001$ \\
Fonte x Dose x Solo & 12 & 7,86 & $<0,0001$ \\
& & C.V. $=20 \%$ & \\
\hline
\end{tabular}


Tabela 12. Parâmetros estimativos das regressões lineares ajustadas para descrever a relação entre fósforo acumulado e as doses de $\mathrm{P}$ em solos de elevada (LV) e baixa (LA) capacidade de fixação de fósforo

\begin{tabular}{|c|c|c|c|}
\hline \multirow{2}{*}{ Fonte de $\mathbf{P}$} & \multirow{2}{*}{ Parâmetro } & \multicolumn{2}{|c|}{ Fósforo acumulado } \\
\hline & & $\mathbf{L V}$ & LA \\
\hline & Bo & $0,77000 * *$ & $0,81 * *$ \\
\hline \multirow[t]{2}{*}{ FMC } & B1 & $0,12049 * *$ & $0,28573^{* *}$ \\
\hline & & $(0,00474)$ & $(0,00911)$ \\
\hline \multirow[t]{2}{*}{ LGSSP } & $\mathrm{B} 2$ & $0,02105^{* *}$ & $0,08744 * *$ \\
\hline & & $(0,00474)$ & $(0,00911)$ \\
\hline \multirow[t]{2}{*}{ MFM } & B3 & $0,08097 * *$ & $0,17075^{* *}$ \\
\hline & & $(0,00474)$ & $(0,00911)$ \\
\hline \multirow[t]{2}{*}{ FR } & B4 & $0,00499 \mathrm{~ns}^{1}$ & $0,03325^{* *}$ \\
\hline & & $(0,00474)$ & $(0,00911)$ \\
\hline \multirow[t]{2}{*}{$\mathrm{H}-14$} & B5 & $0,06163 * *$ & $0,16518^{* *}$ \\
\hline & & $(0,00474)$ & $(0,00911)$ \\
\hline Observações & & 63 & 63 \\
\hline
\end{tabular}



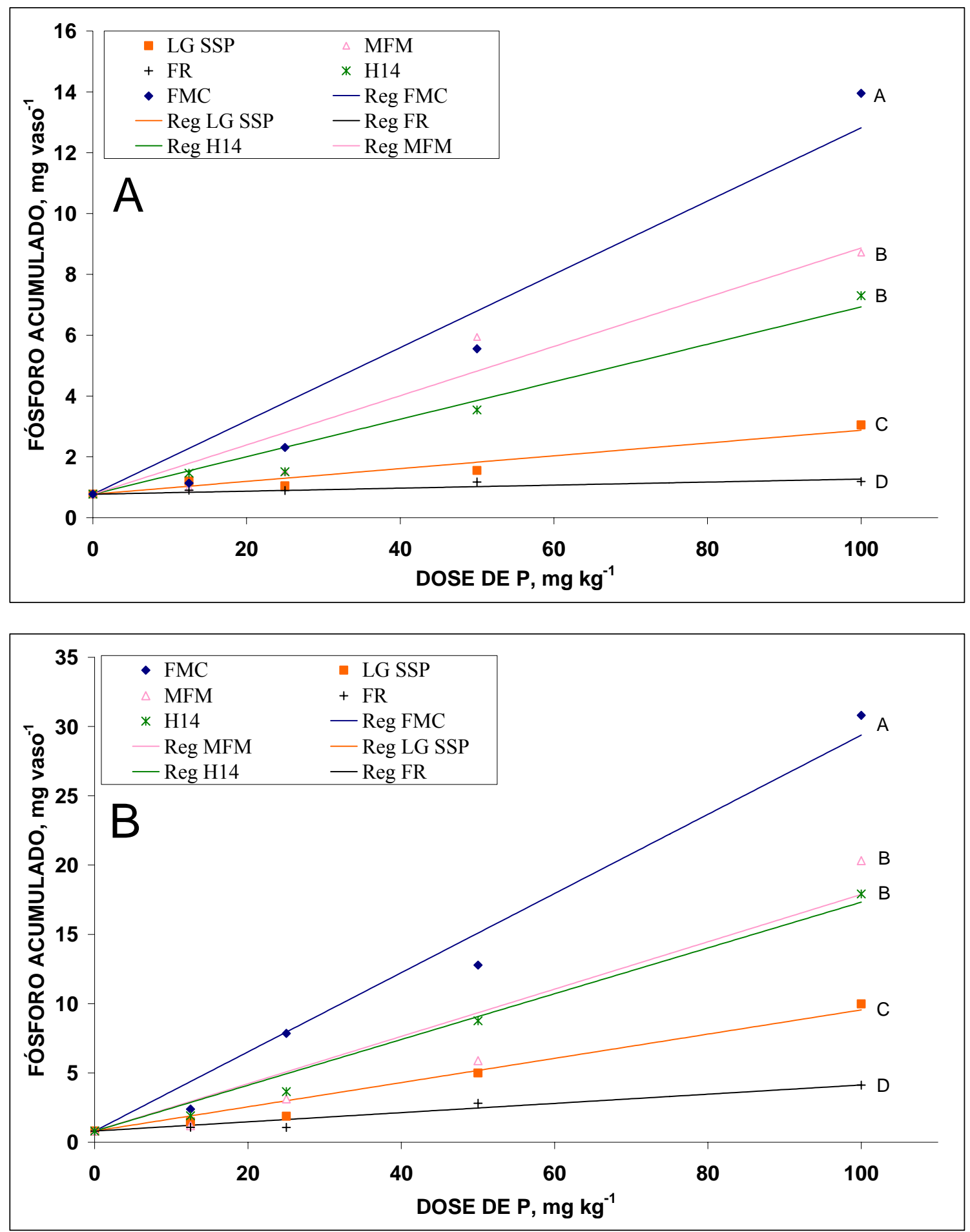

Figura 2 - Efeito das fontes e doses de fósforo no acúmulo de fósforo em plantas de milho cultivadas em amostras de terra de um solo Latossolo Vermelho (A) e um solo Latossolo Amarelo (B). Modelos seguidos da mesma letra não diferem estatisticamente $(\mathrm{P} \leq 0.01)$ 
Tabela 13. Eficiência agronômica relativa $\left(\mathrm{EAR}^{1} ; \%\right)$ das fontes de fósforo em relação ao FMC nos solos de elevada e baixa capacidade de fixação de fósforo

\begin{tabular}{ccc}
\hline Fonte de $\mathbf{P}$ & Fósforo acumulado & LA \\
\hline FMC & 100 & 100 \\
LGSSP & 17 & 31 \\
MFM & 67 & 60 \\
FR & 4 & 12 \\
H-14 & 51 & 58 \\
\hline
\end{tabular}

${ }^{1} \mathrm{EAR}=\left(\beta_{i} / \beta_{F M C}\right) \times 100, \mathrm{i}=$ fonte alternativa 
Tabela 14. Efeito da capacidade de adsorção de fósforo do solo e fonte de fósforo no acúmulo de fósforo por plantas de milho nas doses 12,5;25; 50 e $100 \mathrm{mg} \mathrm{kg}^{-1}$ de fósforo em solos de elevada (LV) e baixa (LA) capacidade de fixação de fósforo

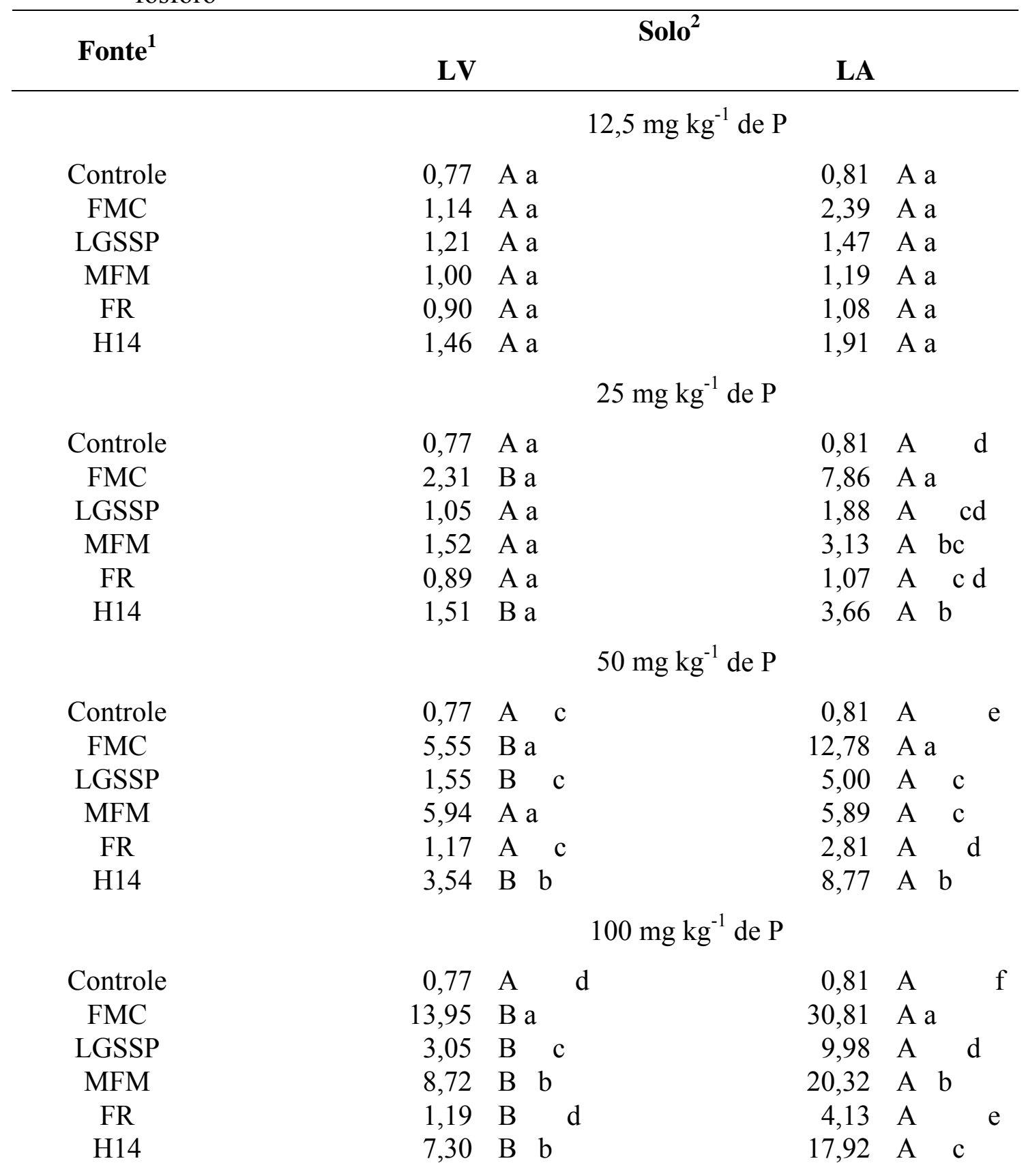

${ }^{1}$ FMC: fosfato monocálcico; LGSSP: low-grade SSP - "superfosfato simples" com baixa solubilidade em água; MFM: multifosfato magnesiano; ARAD: fosfato de rocha de Arad; H-14: impureza catiônica do tipo $\mathrm{H}-14$

2 LV, Latossolo Vermelho; LA, Latossolo Amarelo 
Tabela 15. Eficiência agronômica relativa para o fósforo acumulado das fontes em relação ao FMC para plantas de milho, nas doses 12,5; 25, 50 e $100 \mathrm{mg} \mathrm{kg}^{-1}$ de $\mathrm{P}$ em solos de elevada (LV) e baixa (LA) capacidade de fixação de fósforo

\begin{tabular}{|c|c|c|}
\hline \multirow{2}{*}{ Fonte $^{1}$} & \multicolumn{2}{|c|}{ Solo $^{2}$} \\
\hline & $\mathbf{L V}$ & LA \\
\hline & \multicolumn{2}{|c|}{$12,5 \mathrm{mg} \mathrm{kg}^{-1}$ de $\mathrm{P}$} \\
\hline FMC & 100 & 100 \\
\hline LGSSP & 106 & 62 \\
\hline MFM & 88 & 50 \\
\hline FR & 79 & 45 \\
\hline \multirow[t]{2}{*}{ H14 } & 128 & 80 \\
\hline & \multicolumn{2}{|c|}{$25 \mathrm{mg} \mathrm{kg}^{-1}$ de $\mathrm{P}$} \\
\hline FMC & 100 & 100 \\
\hline LGSSP & 45 & 24 \\
\hline MFM & 66 & 40 \\
\hline FR & 39 & 14 \\
\hline \multirow[t]{2}{*}{$\mathrm{H} 14$} & 65 & 47 \\
\hline & \multicolumn{2}{|c|}{$50 \mathrm{mg} \mathrm{kg}^{-1}$ de $\mathrm{P}$} \\
\hline FMC & 100 & 100 \\
\hline LGSSP & 28 & 39 \\
\hline MFM & 107 & 46 \\
\hline FR & 21 & 22 \\
\hline \multirow[t]{2}{*}{$\mathrm{H} 14$} & 64 & 69 \\
\hline & \multicolumn{2}{|c|}{$100 \mathrm{mg} \mathrm{kg}^{-1}$ de $\mathrm{P}$} \\
\hline $\mathrm{FMC}$ & 100 & 100 \\
\hline LGSSP & 22 & 32 \\
\hline MFM & 62 & 66 \\
\hline FR & 9 & 13 \\
\hline $\mathrm{H} 14$ & 52 & 58 \\
\hline
\end{tabular}

${ }^{1}$ FMC: fosfato monocálcico; LGSSP: low-grade SSP - "superfosfato simples” com baixa solubilidade em água; MFM: multifosfato magnesiano; ARAD: fosfato de rocha de Arad; H-14: impureza catiônica do tipo H-14

2 LV, Latossolo Vermelho; LA, Latossolo Amarelo 
É interessante notar que os dados das Tabelas 10 e 15 não significam que as fontes alternativas são mais eficientes agronomicamente que o padrão no LV. Este, aliás, não era o propósito do estudo. O propósito era o de verificar se fontes de menor solubilidade em água poderiam ter maior eficiência agronômica relativa (padrão $=\mathrm{FMC}$ ) em solos de elevada capacidade de fixação de $\mathrm{P}$, quando comparados aos de baixa. Isto se mostrou verdadeiro, mesmo em um intervalo rápido de tempo, para doses relativamente baixas de $\mathrm{P}$ aplicado. Sugerem-se estudos com tempo mais prolongado em condições de casa-de-vegetação ou campo. É possível que nestas situações as fontes alternativas de $\mathrm{P}$ mostrem EAR superior em solos de elevada capacidade de fixação de $\mathrm{P}$ mesmo em doses mais elevadas.

Os dados sugerem que, nas condições de aplicação utilizadas neste experimento, fontes de menor solubilidade em água podem se constituir em fertilizantes de maior viabilidade agronômica em solos de elevada capacidade de fixação de P. Há necessidade de experimentos mais conclusivos e estudos econômicos sobre o assunto. 


\section{CONCLUSÕES}

A eficiência agronômica relativa das fontes com menor solubilidade em água foi maior no solo de mais elevada capacidade de fixação de fósforo quando da aplicação de doses mais baixas de fósforo, o que confirma a hipótese inicial. Sugerem-se novos estudos em condições de casa de vegetação e campo envolvendo, entre outros itens, situações distintas quanto a fontes (tipo e granulometria), tempo e sistemas de cultivo e solos. Novos dados poderão levar a uma melhor utilização das fontes alternativas contendo menor solubilidade em água em relação às fontes tradicionais de elevada solubilidade em água. 


\section{REFERÊNCIAS BIBLIOGRÁFICAS}

ALCARDE, J.C.; PROCHNOW, L.I. Metodologias de extração para avaliar a eficiência de fertilizantes (compact disc). In: SIMPÓSIO DE FÓSFORO NA AGRICUlturA BRASILEIRA, 1., São Pedro, 2003. Anais. São Pedro: POTAFOS; ANDA, 2003.

ALLEONI, L.R.F. Disciplina LSN 5877: Química de solos com carga variável. Pósgraduação em Solos e Nutrição de Plantas. Piracicaba:ESALQ, 2003. 50 p.

ASSOCIAÇÃO NACIONAL PARA DIFUSÃO DE ADUBOS. Comitê Estatístico. www.anda.org.br. (20 out. 2003).

BIASIOLI, G.M. Influença da força iônica e do $\mathrm{pH}$ na liberação de fósforo de compostos do tipo Fe-K-P. presentes em superfosfatos Piracicaba, 2003. 76p. Dissertação (Mestrado) - Escola Superior de Agricultura "Luiz de Queiroz", Universidade de São Paulo.

BJEONG, G.K.; MASURO, G.; ELICHIT, T. Phosphorus adsorption by soils and it release from them. Chemical Abstracts, v.68, n.7, p.158-163, 1967. 
BRASIL. Ministério da Agricultura. Inspeção e fiscalização da produção e do comércio de fertilizantes, corretivos, inoculantes, estimulantes e biofertilizantes destinados à agricultura:legislação e fiscalização. Brasília: Secretaria Nacional de Defesa Agropecuária, Divisão de Corretivos e Fertilizantes, 1982. 88p.

BRASIL. Ministério de Minas e Energia. Departamento Nacional de Produção mineral. $\begin{array}{llll}\text { Anuário } & \text { mineral } & \text { brasileiro }\end{array}$ http://www.dnpm.gov.br/dnpm_legis/amb2001.html . (15 mar. 2004a. ).

BRASIL. Ministério de Minas e Energia. Departamento Nacional de Produção mineral. Balanço mineral brasilero 2001. http://www.dnpm.gov.br/dnpm_legis/Balanço01/pdf/fosfato.pdf . (15 mar. 2004b.).

BUOL, S.W.; SANCHEZ, P.A.; CATTE, R.B.; GRANGER, M.A. Soil fertility capability classification: a technical soils classification for fertility management. In: BORNEMISZA, E.; ALAVRADO, A. Manejo de suelos en la America tropical. Raleigh: North Carolina State University, 1975. p.126-141.

BUTEGWA, C.N.; MULLINS, G.L.; CHIEN, S.H. Induced phosphorus fixation and the effectiveness of phosphate fertilizer derived from sukulu hills phosphate. Fertilizer Research, v.44, n.3, p.231-240, 1996.

CASAGRANDE, J.C.; CAMARGO, O.A. Adsorção de fosfato em solos com caráter ácrico avaliada por um modelo de complexação de superfície. Revista Brasileira de Ciência do Solo, v.21, n.2, p.353-360, 1997.

CAVALCANTI, J.A.; MELLO, F.A. Fixação porcentual de fósforo por solos da região de Piracicaba. Revista de Agricultura, v.52, n.1, p.93-103, 1977. 
CHIEN, S.H. IFDC's evaluation of modified phosphate rock products. In: RAJAN, S.S.S.; CHIEN, S.H. Direct application of phosphate rock and related technology-latest developments and practical experiences. Kuala Lumpur: IFDC, 2001. p.63-77.

CHIEN, S.H.; HAMMOND, L.L. Agronomic effectiveness of partially acidulated phosphate rock (PAPR) as influenced by soil phosphorus-fixing capacity. Plant and Soil, v.120, p159-164, 1989.

CHIEN, S.H.; MENON, R.G. Factors affecting the agronomic effectiveness of phosphate rock for direct application. Fertilizer Research, v.41, n.2, p.227-234, 1995.

COLLEMAN, R. The mechanism of phosphate fixation by montmorillonitic and kaolinitic clays. Soil Science Society of America Proceedings, v.9, p.72-78, 1944.

COSTA, M.P. Efeito da matéria orgânica sobre alguns atributos do solo. Piracicaba, 1983. 137p. Dissertação (Mestrado) - Escola Superior de Agricultura "Luiz de Queiroz”, Universidade de São Paulo.

DUDAL, R. Dark clay soils and tropical and subtropical regions. Rome:FAO, 1979. 160p.

EMPRESA BRASILEIRA DE PESQUISA AGROPECUÁRIA. Manual de métodos de análise de solo. 2.ed. Rio de Janeiro, 1997. 212p.

FASSBENDER, H. Estudio de fósforo en suelos de América Central. IV. Capacidad de fijación de fósforo y su relación con características edáficas. Turrialba, v.19, n.4, p.497-505, 1969. 
FASSBENDER, H.; IGUE. Y. Comparación de métodos radiométricos y colorimétricos em estúdios sobre retención y transformación de fosfatos en el suelo. Turialba, v.17, p.284-287, 1967.

FLORES, G.C.; TORRES, T.; GONZÁLES, A.; RINCÓN, S. Eficiencia de uso de fósforo en triticale y trigo en dos suelos con diferentes capacidades de fijación de fósforo. Terra, v.19, p.47-54, 2001.

FOX, R.L.; KAMPRATH, E.J. Phosphate sorption isotherms for evaluating the phosphate requirements of soils. Soil Science Society of America Journal, v.34, n.2, p.902-907, 1970.

GALINDO, G.G. Phosphate sorption capacity of clay fraction of soils derived from volcanic ash. Phosphorus in Agriculture, v.61, p.57-61, 1972.

HAVLIN, J.L.; BEATON, J.D.; TISDALE, S.L.; NELSON,W.L. Soil fertility and fertilizers: an introduction to nutrient management. Sydney: Prentice Hall, 1999. 498 p.

HAMMOND, L.L.; LEÓN, L.A. Relative agronomic effectiveness of some latin america phosphate rocks in colombian soils. In: INTERNATIONAL CONGRESS OF PHOSPHORUS COMPOUNDS, 3., Brusels, 1983. Anais. Brusels, 1983. p.124-125

HAMMMOND, L.L.; CHIEN, S.H.; EASTERWOOD, G.W. Agronomic effectiveness of Bayovar phosphate rock in soil with induced phosphorus retention. Soil Science Society of America Journal, v.50, n.3, p.1601-1606, 1986. 
HASSEMAN, J.F.; LERH, J.R.; SMITH, J.P. Mineralogical character of some iron and aluminum phosphates containing potassium and ammonium. Soil Science Society of America Proceedings, v.15, n.1, p.76-84, 1950.

HEWALL, J.B. The role of soil clay minerals in phosphorus fixation. Soil Science, v.83, n.2, p.101-108, 1957.

HINGSTON, F.J.; ATKINTSON R.J.; POSNER, A.M.; QUIRK, J.P. Specific absorption of anions. Nature, v.215, p.1459-1461, 1967.

JACKSON, M.L. Soil chemical analysis: advanced course. Madison: WISC, 1969. 215p.

JENNY, H. Reflections on the soil acidity merry-go-round. Soil Science Society of America Proceedings, v.25, n.5, p.428-432, 1961.

JUO, A.S.R.; FOX, R.L. Phosphate sorption characteristic of some bench-mark soils of West Africa. Soil Science, v.124, n.6, p.370-376, 1977.

KER, J.C. Mineralogia, sorção e desorção de fosfato, magnetização e elementos traços de latossolos do Brasil. Viçosa, 1995. 181p. Tese (Doutorado) - Universidade Federal de Viçosa.

KHASAWNEH, F.E.; DOLL, E.C. The use of phosphate rock for direct application to soils. Advances in Agronomy, v.30, p.159-206, 1978. 
KLAGES, M.G. Phosphorus adsorption and release by soils clay mineral. Agronomy Abstract, v.9, p.83-85, 1969.

KUO, S.; LOSTE, E. Kinetics of phosphorus adsorption by calcium carbonate and kaolinite. Soil Science Society of America Proceedings, v.36, n.3, p.725-729, 1972.

LEAL, J.R.; VELLOSO, A.C. Adsorção de fosfatos sob solos de vegetação de cerrado. Pesquisa Agropecuária Brasileira, v.8, p.81-88, 1973.

LEHR, J.R. Phosphate raw materials and fertilizers, part I - a look ahead. In: KHASAWNEH, F.E.; SAMPLE, E.C.; KAMPRATH, E.J. The role of phosphorus in agriculture. Madison: American Society of Agronomy, 1980. p.81-120.

LEON, L.A. La experiencia del centro internacional para el desarrollo de fertilizantes en el uso de rocas fosfóricas en América Latina. Revista de la Facultad de Agronomia, Universidad Central de Venezuela, v.17, p.49-66, 1991.

LEON, L.A.; FENSTER, W.E.; HAMMOND L.L. Agronomyc potential of eleven phosphates rock from Brazil, Colombia, Perú and Venezuela. Soil Science Society of America Journal, v.50, n.3, p.798-802, 1986.

LOEPPERT, R.L.; INSKEEP, W.P. Iron. In: BIGHAM, J.M. (Ed.). Methods of soil analysis. pt.3: chemical methods. Madison: Soil Science Society of America; American Society of Agronomy, 1996. cap.23, p.639-664. 
LOPES, A.S. Reservas de fosfatos e produção de fertilizantes fosfatados no Brasil e no mundo (compact disc). In: SIMPÓSIO DE FÓSFORO NA AGRICULTURA BRASILEIRA, 1., São Pedro, 2003. Anais. São Pedro: POTAFOS; ANDA, 2003.

LOPES, A.S.; COX, F.R. A survey of the fertility status of surface soils under cerrado vegetation in Brazil. Soil Science Society of America Journal, v. 41, n.3, p.742747, 1977.

LYNDSAY, W.L.; MORENO, E.C. Phosphate phase equilibria in soils. Soil Science Society of America Proceedings, v.24, n.1, p.177-183, 1960.

MALAVOLTA, E. Manual de química agrícola. São Paulo: Ceres, 1976. 528p.

MALAVOLTA, E.; VITTI, G.C; OLIVEIRA, S.A. Avaliação do estado nutricional das plantas : princípios e aplicações. São Paulo: POTAFOS, 1997. 319p.

MELGAR. R.J.; SMYTH, T.J.; SANCHEZ, P.A.; CRAVO M.S. Fertilizer nitrogen movement in a Central Amazon Oxisol and Entisol cropped to corn. Fertilizer Research, v.31, n.2, p.241-252, 1992.

MELLO, F.A.F. Capacidade de fixação de fosfato de alguns solos do município de Piracicaba. Revista de Agricultura, v.43, p.23-27, 1968.

MELLO, F.A.F Fatores que afetam a fixação do fósforo no solo: o efeito isolado e dentro de um contexto. Revista de Agricultura, v.65, p.333-337, 1985. 
MULKJADI, D.; POSNER, A.M.; QUIRK, J.P The mecanism of phosphate adsorption by kaolinite, gibbsite and pseudobohemite. Journal of Soil Science, v.17, n.2, p. 212-247, 1966.

NAGARAJAH, S.H.; POSNER, M.; KIRK, J. Desorption of phosphate from kaolinite, citrate and bicarbonate. Soil Science Society of America Proceedings, v.21, n.1, p.144-149, 1968.

NOVAIS, R.F.; SMYTH, J.T. Fósforo em solo e planta em condições tropicais. Viçosa: UFV, DPS, 1999. 399p.

NUÑES, R. La roca fosfórica. Cochabamba: GLIRF, 1984. v.2, 245p.

OBIHARA, C.H.; RUSSEL, E.W. Specific adsorption of silicate and phosphate by soils. Journal of Soil Science, v.23, n.1, p.105-107, 1972.

OLSON, R.A.; ARMY, T.J.; HANWAY, J.J.; KILMER, V.S. Fertilizer phosphorus interaction in alkaline soils. Soil Science Society of America Proceedings, v.3, n.1, p.153-180, 1871.

PARFITT, R.L. Anion adsoption by soils and soils materials. Advances in Agronomy. v.30, p.1-50, 1978.

PARFITT, R.L.; ATKINSON, R.J.; SMART, R.C. The mechanism of phosphate fixation by iron oxides. Soil Science Society of America Journal, v.39, n.3, p837841, 1975. 
PRATT, P.F.; PETERSON, F.F.; HOLZHEY, C.S. Qualitative mineralogical and chemical properties of a few soils from São Paulo, Brazil. Turrialba, v.19, n.4, p.1969.

PROCHNOW, L.I. Disponibilidade do fósforo da fração solúvel em citrato neutro de amônio e insolúvel em água de fosfatos acidulados. Piracicaba, 1996. 160p. Tese (Doutorado) - Escola Superior de Agricultura “Luiz de Queiroz”, Universidade de São Paulo.

PROCHNOW, L.I. Eficiência agronômica de fosfatos totalmente acidulados (compact disc). In: SIMPÓSIO DE FÓSFORO NA AGRICULTURA BRASILEIRA, 1., São Pedro, 2003. Anais. São Pedro: POTAFOS; ANDA, 2003.

RAIJ, B.van. Fertilidade do solo e adubação. Piracicaba: Ceres; Potafos, 1991. 343p.

RAIJ, B.van. Métodos de diagnose de fósforo em uso no Brasil (compact disc). In: SIMPÓSIO DE FÓSFORO NA AGRICULTURA BRASILEIRA, 1., São Pedro, 2003. Anais. São Pedro: POTAFOS; ANDA, 2003.

RAIJ, B.van; ANDRADE, J.C.; CANTARELLA, H.; QUAGGIO, J.A. Recomendações de adubação e calagem para o Estado de São Paulo. Campinas: Instituto Agronômico, 1996. 285p.

RAIJ, B.van; ANDRADE, J.C.; CANTARELLA, H.; QUAGGIO, J.A. Análise química para avaliação da fertilidade de solos tropicais. Campinas: Instituto Agronômico, 2001. 285p. 
RODRIGUES, M.R. Fatores que afetam a fixação de fosfatos nos solos do estado de São Paulo. Piracicaba, 1980. 88p. Dissertação (Mestrado) - Escola Superior de Agricultura “Luiz de Queiroz”, Universidade de São Paulo.

SAMPLE, E.C.R.J.; SOPER, G.J.; RACZ, G.J. Reaction of phosphate fertilizer in soils. In: KHASAWNEH, F.E.; SAMPLE, E.C.; KAMPRATH, E.J. The role of phosphorus in agriculture. Madison: ASA; CSSA; SSSA, 1980. cap.11, p.263310.

SANCHEZ, P.A. Properties and management of soils in the tropics. New York: Wiley Interscience, 1976. 618p.

SANCHEZ, P.A. Suelos del trópico: características y manejo. San José: IICA, 1981. 660p.

SANCHEZ, P.A.; LOGAN, T.J. Myths and science about the chemistry and fertility of soils in the tropics. In: SANCHES, P.A.; LAL, R. Myths and science of soils of the tropics. Madison: SSSA; ASA, 1992. cap.3, p.35-46.

SANCHEZ, P.A.; SALINAS, J.C. Low imput technology for managing oxisols and ultisols in tropical America. Advances in Agronomy, v.34, p.279-406, 1981.

SANCHEZ, P.A.; UHEARA, G. Management considerations for acid soils with high phoshphorus fixation capacity. In: KHASAWNEH, F.E.; SAMPLE, E.C.; KAMPRATH, E.J. The role of phosphorus in agriculture. Madison: ASA; CSSA; SSSA, 1980. cap.17, p.471-514.

SILVEIRA, R.I. Tecnologia de fabricação e características gerais de adubos. Piracicaba:ESALQ, 2000. 120p. 
SMITH, T.J.; SANCHEZ, P.A. Phosphate rock dissolution and availability in cerrado soils affected by phosphorus sorption capacity. Soil Science Society of America Journal, v.46, n.2, p.339-345, 1982.

SYERS, J.K.; EVANS, T.D.; WILLIAMS, J.D.; MURDOCK, T.J. Phosphate sorption parameters of representative soils from Rio Grande do Sul, Brazil. Soil Science, v.112, n.3, p.267-275, 1971.

THOMAZI, M.D. Fixação de fosfato por solos do município de piracicaba. Piracicaba, 1988. 67p. Tese (Doutorado) - Escola Superior de Agricultura “Luiz de Queiroz”, Universidade de São Paulo. 
APÊNDICES 
APÊNDICE 1. Tratamentos utilizados no experimento para avaliação das fontes de solubilidade variável em água em solos de elevada (LV) e baixa (LA) capacidade de fixação de fósforo

\begin{tabular}{cccccccccc}
\hline Trat. $^{1}$ & Cultura & Fonte $^{2}$ & Dose & Solo $^{3}$ & Trat. & Cultura & Fonte P & Dose & Solo \\
\hline & & & mg kg $^{-1}$ & & & & & mg kg $^{-1}$ & \\
1 & Milho & Control & 0 & LV & 22 & Milho & controle & 0 & LA \\
2 & Milho & FMC & 12,5 & LV & 23 & Milho & FMC & 12,5 & LA \\
3 & Milho & FMC & 25 & LV & 24 & Milho & FMC & 25 & LA \\
4 & Milho & FMC & 50 & LV & 25 & Milho & FMC & 50 & LA \\
5 & Milho & FMC & 100 & LV & 26 & Milho & FMC & 100 & LA \\
6 & Milho & LGSSP & 12,5 & LV & 27 & Milho & LGSSP & 12,5 & LA \\
7 & Milho & LGSSP & 25 & LV & 28 & Milho & LGSSP & 25 & LA \\
8 & Milho & LGSSP & 50 & LV & 29 & Milho & LGSSP & 50 & LA \\
9 & Milho & LGSSP & 100 & LV & 30 & Milho & LGSSP & 100 & LA \\
10 & Milho & MFM & 12,5 & LV & 31 & Milho & MFM & 12,5 & LA \\
11 & Milho & MFM & 25 & LV & 32 & Milho & MFM & 25 & LA \\
12 & Milho & MFM & 50 & LV & 33 & Milho & MFM & 50 & LA \\
13 & Milho & MFM & 100 & LV & 34 & Milho & MFM & 100 & LA \\
14 & Milho & FR & 12,5 & LV & 35 & Milho & FR & 12,5 & LA \\
15 & Milho & FR & 25 & LV & 36 & Milho & FR & 25 & LA \\
16 & Milho & FR & 50 & LV & 37 & Milho & FR & 50 & LA \\
17 & Milho & FR & 100 & LV & 38 & Milho & FR & 100 & LA \\
18 & Milho & H-14 & 12,5 & LV & 39 & Milho & H-14 & 12,5 & LA \\
19 & Milho & H-14 & 25 & LV & 40 & Milho & H-14 & 25 & LA \\
20 & Milho & H-14 & 50 & LV & 41 & Milho & H-14 & 50 & LA \\
21 & Milho & H-14 & 100 & LV & 42 & Milho & H-14 & 100 & LA \\
& & & & & & & & &
\end{tabular}

${ }^{1}$ Cada tratamento constou de três repetições

${ }^{2}$ FMC = fosfato monocálcico; LGSSP = low-grade SSP - "superfosfato simples” com baixa solubilidade em água ; MFM = multifosfato magnesiano; FR = fosfato de rocha de Arad; H-14= impureza catiônica do tipo H-14. No caso do experimento de efeito residual não foi aplicado fósforo

${ }^{3}$ LV: solo de elevada capacidade de fixação de P (Latossolo Vermelho); LA: solo de baixa capacidade de fixação de fósforo (Latossolo Amarelo) 
APÊNDICE 2. Efeito das doses, fontes e solos na produção de matéria seca da parte aérea de plantas de milho

\begin{tabular}{|c|c|c|c|c|c|c|c|}
\hline \multirow{2}{*}{ Trat. } & \multirow{2}{*}{ Fonte $^{1}$} & \multirow{2}{*}{ Dose } & \multirow{2}{*}{ Solo $^{2}$} & \multicolumn{3}{|c|}{ Repetição } & \multirow{2}{*}{ Média } \\
\hline & & & & $\mathbf{A}$ & B & C & \\
\hline & \multicolumn{3}{|c|}{$\mathrm{mg} \mathrm{kg}^{-1}$} & \multicolumn{4}{|c|}{ gramas por vaso } \\
\hline 1 & Controle & 0 & LV & 1.46 & 1.5 & 1.1 & 1.35 \\
\hline 2 & FMC & 12.5 & LV & 2.00 & 1.64 & 1.74 & 1.79 \\
\hline 3 & FMC & 25 & $\mathrm{LV}$ & 2.66 & 2.23 & 3.02 & 2.64 \\
\hline 4 & FMC & 50 & $\mathrm{LV}$ & 6.4 & 6.47 & 6.77 & 6.55 \\
\hline 5 & FMC & 100 & $\mathrm{LV}$ & 13.08 & 10.09 & 10.71 & 11.29 \\
\hline 6 & SSP & 12.5 & $\mathrm{LV}$ & 2.08 & 1.47 & 1.61 & 1.72 \\
\hline 7 & SSP & 25 & $\mathrm{LV}$ & 1.23 & 1.2 & 1.69 & 1.37 \\
\hline 8 & SSP & 50 & $\mathrm{LV}$ & 2.09 & 2.17 & 2.17 & 2.14 \\
\hline 9 & SSP & 100 & $\mathrm{LV}$ & 2.46 & 4.5 & 3.47 & 3,48 \\
\hline 10 & MFM & 12.5 & LV & 1.86 & 1.59 & 1.48 & 1.64 \\
\hline 11 & MFM & 25 & $\mathrm{LV}$ & 2.25 & 2.2 & 2.29 & 2.25 \\
\hline 12 & MFM & 50 & $\mathrm{LV}$ & 4.2 & 4.31 & 7.81 & 5.44 \\
\hline 13 & MFM & 100 & $\mathrm{LV}$ & 7,18 & 7,36 & 10,35 & 8,30 \\
\hline 14 & FR & 12,5 & LV & 2.07 & 1.27 & 1.12 & 1.49 \\
\hline 15 & FR & 25 & $\mathrm{LV}$ & 1.52 & 1.12 & 1.44 & 1.36 \\
\hline 16 & FR & 50 & $\mathrm{LV}$ & 1.52 & 2.07 & 1.9 & 1.83 \\
\hline 17 & FR & 100 & $\mathrm{LV}$ & 1.76 & 2.08 & 1.88 & 1.91 \\
\hline 18 & $\mathrm{H}-14$ & 12.5 & $\mathrm{LV}$ & 2.52 & 2.05 & 1.73 & 2.10 \\
\hline 19 & $\mathrm{H}-14$ & 25 & $\mathrm{LV}$ & 2.5 & 2.18 & 1.89 & 2.19 \\
\hline 20 & $\mathrm{H}-14$ & 50 & $\mathrm{LV}$ & 4.18 & 4.1 & 4,34 & 4.21 \\
\hline 21 & $\mathrm{H}-14$ & 100 & $\mathrm{LV}$ & 8.45 & 7.25 & 6.82 & 7.51 \\
\hline 22 & Controle & 0 & LA & 1.21 & 1.21 & 1.12 & 1.18 \\
\hline 23 & FMC & 12.5 & LA & 2.9 & 2.18 & 2.58 & 2.55 \\
\hline 24 & FMC & 25 & LA & 7.41 & 7.42 & 6.63 & 7.15 \\
\hline 25 & FMC & 50 & LA & 9.34 & 12.28 & 9.37 & 10.33 \\
\hline 26 & FMC & 100 & LA & 17.73 & 16.17 & 16.63 & 16.84 \\
\hline 27 & SSP & 12.5 & LA & 1.69 & 1.94 & 1.68 & 1.77 \\
\hline 28 & SSP & 25 & LA & 1.42 & 2.14 & 2.59 & 2.05 \\
\hline 29 & SSP & 50 & LA & 4,42 & 4.8 & 4.17 & 4.46 \\
\hline 30 & SSP & 100 & LA & 8,45 & 7.57 & 7,11 & 7,71 \\
\hline 31 & MFM & 12.5 & LA & 1.63 & 1.08 & 1.33 & 1.35 \\
\hline 32 & MFM & 25 & LA & 3,46 & 2.36 & 2.33 & 2.72 \\
\hline 33 & MFM & 50 & LA & 4.48 & 5.25 & 5.35 & 5.03 \\
\hline 34 & MFM & 100 & LA & 12.12 & 13.68 & 12.97 & 12.92 \\
\hline 35 & FR & 12.5 & LA & 1.6 & 1.34 & 0.82 & 1.25 \\
\hline 36 & $\mathrm{FR}$ & 25 & LA & 1.28 & 1.97 & 1.09 & 1,45 \\
\hline 37 & FR & 50 & LA & 2.63 & 2.8 & 3.36 & 2.93 \\
\hline 38 & FR & 100 & LA & 4.00 & 4.19 & 4,14 & 4.11 \\
\hline 39 & $\mathrm{H}-14$ & 12.5 & LA & 1.81 & 1.95 & 2.47 & 2.08 \\
\hline 40 & $\mathrm{H}-14$ & 25 & LA & 3.86 & 3.63 & 3.69 & 3.73 \\
\hline 41 & $\mathrm{H}-14$ & 50 & LA & 8.05 & 6.63 & 6.61 & 7.10 \\
\hline 42 & $\mathrm{H}-14$ & 100 & LA & 10.57 & 10.5 & 12.04 & 11.04 \\
\hline
\end{tabular}

${ }^{1}$ FMC: fosfato monocálcico; LGSSP: low-grade SSP - "superfosfato simples” com baixa solubilidade em água; MFM: multifosfato magnesiano; ARAD: fosfato de rocha de Arad; H-14: impureza catiônica do tipo $\mathrm{H}-14$

${ }^{2}$ LV, Latossolo Vermelho; LA, Latossolo Amarelo 
APÊNDICE 3. Efeito das doses, fontes e solos na concentração de P da parte aérea de plantas de milho

\begin{tabular}{|c|c|c|c|c|c|c|c|}
\hline \multirow{2}{*}{ Trat. } & \multirow{2}{*}{ Fonte $^{1}$} & \multirow{2}{*}{ Dose } & \multirow{2}{*}{ Solo $^{2}$} & \multicolumn{3}{|c|}{ Repetição } & \multirow{2}{*}{ Média } \\
\hline & & & & A & B & C & \\
\hline & \multicolumn{3}{|c|}{$\mathrm{mg} \mathrm{kg}{ }^{-1}$} & \multicolumn{4}{|c|}{$\mathrm{g} \mathrm{kg}^{-1}$} \\
\hline 1 & Controle & 0 & LV & 0.51 & 0.56 & 0.67 & 0.58 \\
\hline 2 & FMC & 12.5 & LV & 0.58 & 0.71 & 0.62 & 0.64 \\
\hline 3 & FMC & 25 & $\mathrm{LV}$ & 0.81 & 0.93 & 0.89 & 0.88 \\
\hline 4 & FMC & 50 & $\mathrm{LV}$ & 0.82 & 0.84 & 0.88 & 0.85 \\
\hline 5 & FMC & 100 & $\mathrm{LV}$ & 1,21 & 1,28 & 1,23 & 1,24 \\
\hline 6 & SSP & 12.5 & LV & 0.79 & 0.67 & 0.62 & 0.69 \\
\hline 7 & SSP & 25 & $\mathrm{LV}$ & 0.55 & 0.92 & 0.81 & 0.76 \\
\hline 8 & SSP & 50 & $\mathrm{LV}$ & 0.70 & 0.66 & 0.81 & 0.72 \\
\hline 9 & SSP & 100 & LV & 0.86 & 0.89 & 0.87 & 0.87 \\
\hline 10 & MFM & 12.5 & LV & 0.70 & 0.61 & 0.50 & 0.60 \\
\hline 11 & MFM & 25 & $\mathrm{LV}$ & 0.59 & 0.68 & 0.76 & 0.68 \\
\hline 12 & MFM & 50 & LV & 1.28 & 1.28 & 0.89 & 1.15 \\
\hline 13 & MFM & 100 & $\mathrm{LV}$ & 1.09 & 1.04 & 1.03 & 1.05 \\
\hline 14 & FR & 12.5 & $\mathrm{LV}$ & 0.59 & 0.51 & 0.75 & 0.62 \\
\hline 15 & FR & 25 & LV & 0.67 & 0.58 & 0.69 & 0.65 \\
\hline 16 & FR & 50 & LV & 0.76 & 0.60 & 0.58 & 0.65 \\
\hline 17 & FR & 100 & $\mathrm{LV}$ & 0.60 & 0.68 & 0.58 & 0.62 \\
\hline 18 & H-14 & 12.5 & LV & 0.76 & 0.70 & 0.61 & 0.69 \\
\hline 19 & $\mathrm{H}-14$ & 25 & $\mathrm{LV}$ & 0.64 & 0.73 & 0.71 & 0.69 \\
\hline 20 & $\mathrm{H}-14$ & 50 & $\mathrm{LV}$ & 0.77 & 0.90 & 0.85 & 0.84 \\
\hline 21 & H-14 & 100 & LV & 0.92 & 1.13 & 0.87 & 0.97 \\
\hline 22 & Controle & 0 & LA & 0,63 & 0,70 & 0,73 & 0,69 \\
\hline 23 & FMC & 12.5 & LA & 0.95 & 0.97 & 0.89 & 0.94 \\
\hline 24 & FMC & 25 & LA & 1.11 & 1.12 & 1.06 & 1.10 \\
\hline 25 & FMC & 50 & LA & 1.44 & 1.30 & 0.95 & 1.23 \\
\hline 26 & FMC & 100 & LA & 1.97 & 1.85 & 1.65 & 1.83 \\
\hline 27 & SSP & 12.5 & LA & 0.81 & 0.83 & 0.85 & 0.83 \\
\hline 28 & SSP & 25 & LA & 1.06 & 0.90 & 0.85 & 0.94 \\
\hline 29 & SSP & 50 & LA & 1.19 & 1.01 & 1.17 & 1.12 \\
\hline 30 & SSP & 100 & LA & 1.23 & 1.32 & 1.35 & 1.30 \\
\hline 31 & MFM & 12.5 & LA & 0.79 & 1.01 & 0.91 & 0.90 \\
\hline 32 & MFM & 25 & LA & 1.02 & 1.32 & 1.19 & 1.17 \\
\hline 33 & MFM & 50 & LA & 1.33 & 1.17 & 1.04 & 1.18 \\
\hline 34 & MFM & 100 & LA & 1.60 & 1.58 & 1.54 & 1.57 \\
\hline 35 & FR & 12.5 & LA & 0.82 & 0.85 & 0.97 & 0.88 \\
\hline 36 & FR & 25 & LA & 0.70 & 0.73 & 0.80 & 0.74 \\
\hline 37 & FR & 50 & LA & 0.94 & 0.95 & 0.98 & 0.96 \\
\hline 38 & FR & 100 & LA & 1.07 & 0.79 & 1.15 & 1.01 \\
\hline 39 & H-14 & 12.5 & LA & 0.86 & 0.82 & 1.04 & 0.91 \\
\hline 40 & $\mathrm{H}-14$ & 25 & LA & 0.92 & 1.01 & 1.02 & 0.98 \\
\hline 41 & $\mathrm{H}-14$ & 50 & LA & 1.07 & 1.35 & 1.32 & 1.25 \\
\hline 42 & $\mathrm{H}-14$ & 100 & LA & 1.75 & 1.54 & 1.59 & 1.63 \\
\hline
\end{tabular}

${ }^{1}$ FMC: fosfato monocálcico; LGSSP: low-grade SSP - "superfosfato simples" com baixa solubilidade em água; MFM: multifosfato magnesiano; ARAD: fosfato de rocha de Arad; H-14: impureza catiônica do tipo $\mathrm{H}-14$

${ }^{2}$ LV, Latossolo Vermelho; LA, Latossolo Amarelo 
APÊNDICE 4. Efeito das doses, fontes e solos no acúmulo de fósforo na parte aérea de plantas de milho

\begin{tabular}{|c|c|c|c|c|c|c|c|}
\hline \multirow{2}{*}{ Trat. } & \multirow{2}{*}{ Fonte $^{1}$} & \multirow{2}{*}{ Dose } & \multirow{2}{*}{ Solo $^{2}$} & \multicolumn{3}{|c|}{ Repetição } & \multirow{2}{*}{ Média } \\
\hline & & & & A & B & C & \\
\hline
\end{tabular}

\begin{tabular}{|c|c|c|c|c|c|c|c|}
\hline & \multicolumn{3}{|c|}{$\mathrm{mg} \mathrm{kg}^{-1}$} & \multicolumn{4}{|c|}{$\mathrm{mg}$ vaso $^{-1}$} \\
\hline 1 & Controle & 0 & $\mathrm{LV}$ & 0.74 & 0.84 & 0.74 & 0.77 \\
\hline 2 & FMC & 12.5 & $\mathrm{LV}$ & 1.17 & 1.16 & 1.08 & 1.14 \\
\hline 3 & FMC & 25 & $\mathrm{LV}$ & 2.15 & 2.08 & 2.70 & 2.31 \\
\hline 4 & FMC & 50 & $\mathrm{LV}$ & 5.28 & 5.41 & 5.97 & 5.55 \\
\hline 5 & FMC & 100 & LV & 15.80 & 12.87 & 13.18 & 13.95 \\
\hline 6 & SSP & 12.5 & $\mathrm{LV}$ & 1.63 & 0.99 & 0.99 & 1.21 \\
\hline 7 & SSP & 25 & $\mathrm{LV}$ & 0.68 & 1.10 & 1.37 & 1.05 \\
\hline 8 & SSP & 50 & $\mathrm{LV}$ & 1.47 & 1.44 & 1.75 & 1.55 \\
\hline 9 & SSP & 100 & LV & 2.11 & 4.02 & 3.02 & 3.05 \\
\hline 10 & MFM & 12.5 & $\mathrm{LV}$ & 1.30 & 0.96 & 0.75 & 1.00 \\
\hline 11 & MFM & 25 & LV & 1.34 & 1.49 & 1.73 & 1.52 \\
\hline 12 & MFM & 50 & $\mathrm{LV}$ & 5.36 & 5.50 & 6.97 & 5.94 \\
\hline 13 & MFM & 100 & $\mathrm{LV}$ & 7.83 & 7.69 & 10.64 & 8.72 \\
\hline 14 & FR & 12.5 & $\mathrm{LV}$ & 1.23 & 0.65 & 0.84 & 0.90 \\
\hline 15 & FR & 25 & LV & 1.02 & 0.65 & 0.99 & 0.89 \\
\hline 16 & FR & 50 & $\mathrm{LV}$ & 1.16 & 1.24 & 1.11 & 1.17 \\
\hline 17 & FR & 100 & LV & 1.06 & 1.42 & 1.08 & 1.19 \\
\hline 18 & $\mathrm{H}-14$ & 12.5 & LV & 1.91 & 1.43 & 1.06 & 1.46 \\
\hline 19 & H-14 & 25 & $\mathrm{LV}$ & 1.60 & 1.59 & 1.35 & 1.51 \\
\hline 20 & H-14 & 50 & $\mathrm{LV}$ & 3.24 & 3.68 & 3.70 & 3.54 \\
\hline 21 & $\mathrm{H}-14$ & 100 & $\mathrm{LV}$ & 7.73 & 8.23 & 5.93 & 7.30 \\
\hline 22 & Controle & 0 & LA & 0.77 & 0.85 & 0.82 & 0.81 \\
\hline 23 & FMC & 12.5 & LA & 2.77 & 2.11 & 2.29 & 2.39 \\
\hline 24 & FMC & 25 & LA & 8.24 & 8.34 & 7.00 & 7.86 \\
\hline 25 & FMC & 50 & LA & 13,44 & 16.01 & 8.89 & 12.78 \\
\hline 26 & FMC & 100 & LA & 35.01 & 29.93 & 27.50 & 30.81 \\
\hline 27 & SSP & 12,5 & LA & 1,37 & 1,61 & 1,43 & 1,47 \\
\hline 28 & SSP & 25 & LA & 1.51 & 1.93 & 2.20 & 1.88 \\
\hline 29 & SSP & 50 & LA & 5.27 & 4.85 & 4.87 & 5.00 \\
\hline 30 & SSP & 100 & LA & 10.35 & 10.00 & 9.59 & 9.98 \\
\hline 31 & MFM & 12.5 & LA & 1.28 & 1.09 & 1.21 & 1.19 \\
\hline 32 & MFM & 25 & LA & 3.52 & 3.10 & 2.76 & 3.13 \\
\hline 33 & MFM & 50 & $\mathrm{LA}$ & 5.94 & 6.14 & 5.59 & 5.89 \\
\hline 34 & MFM & 100 & LA & 19.36 & 21.62 & 19.98 & 20.32 \\
\hline 35 & FR & 12.5 & LA & 1.32 & 1.14 & 0.79 & 1.08 \\
\hline 36 & $\mathrm{FR}$ & 25 & LA & 0.90 & 1.45 & 0.87 & 1.07 \\
\hline 37 & FR & 50 & LA & 2.48 & 2.67 & 3.28 & 2.81 \\
\hline 38 & FR & 100 & LA & 4.29 & 3.32 & 4.77 & 4.13 \\
\hline 39 & $\mathrm{H}-14$ & 12.5 & LA & 1.55 & 1.61 & 2.58 & 1.91 \\
\hline 40 & H-14 & 25 & LA & 3.53 & 3.67 & 3.77 & 3.66 \\
\hline 41 & $\mathrm{H}-14$ & 50 & LA & 8.59 & 8,98 & 8.73 & 8.77 \\
\hline 42 & $\mathrm{H}-14$ & 100 & LA & 18.55 & 16.12 & 19.09 & 17.92 \\
\hline
\end{tabular}

